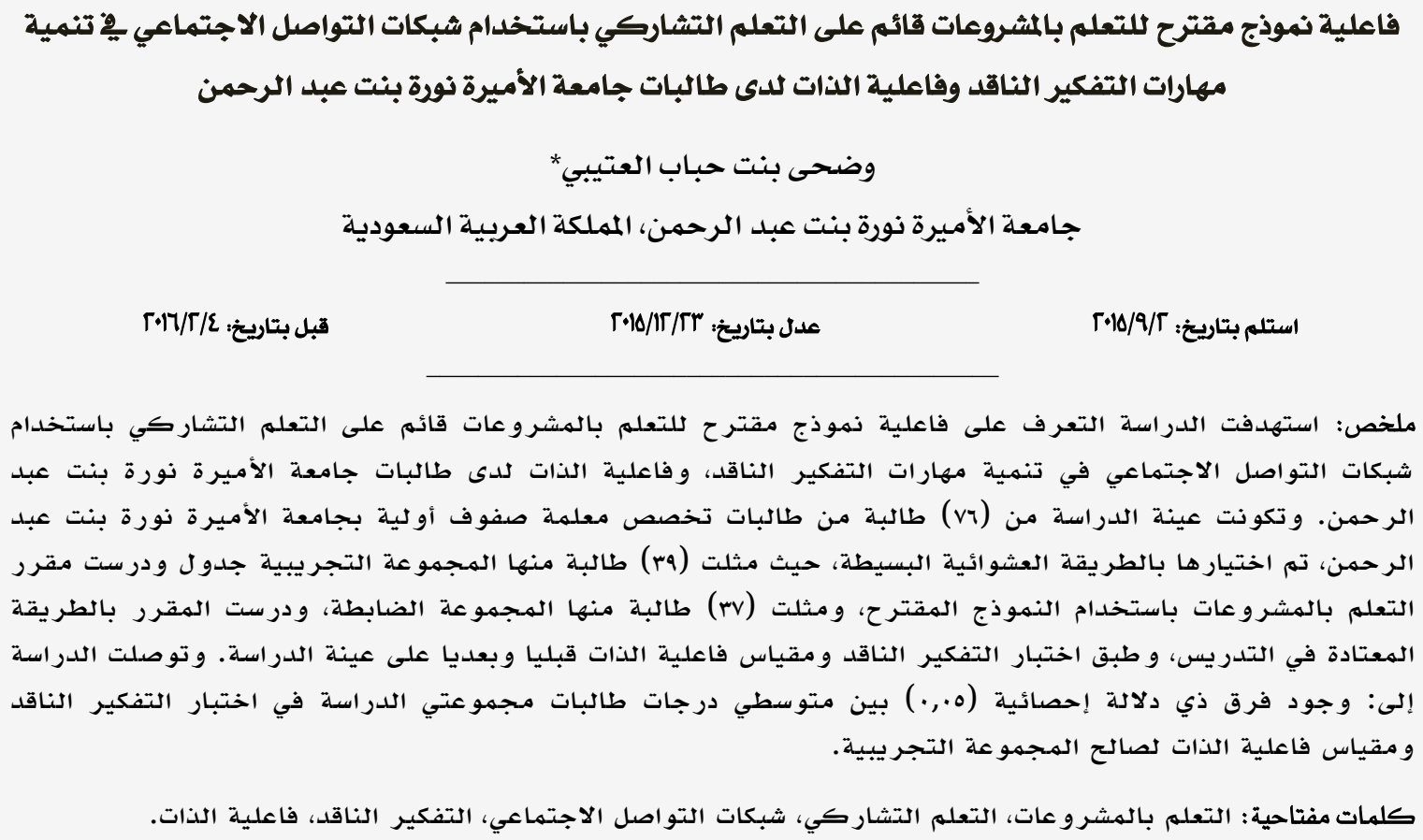

\title{
The Effectiveness of a Suggested Model for Learning through Projects Based on Shared Learning Using Social Communication Networks in Developing Critical Thinking Skills and Self-Efficiency in PNU Students
}

Wadha H. Al-Otaibi*

Princess Nourah bint Abdulrahman University, Kingdom of Saudi Arabia

\begin{abstract}
The study aimed at identifying the effectivness of a suggested model for learning through projects based on shared learning in developing critical thinking skills and self-efficiency in Princess Nourah bint Abdularhman University (PNU). The study included a sample of 76 students from the specialization of primary level teachers in PNU randomly chosen, in which 39 students represented the experimental group. This group was taught the course of learning through projects using a suggested model. The other 37 students formed the control group and were taught the course in the conventional teaching manner. The critical thinking test and the self-efficiency scale were both administered before and after the experiment. The study revealed a significant difference $(p<0.05)$ in the means between the experimental and control groups in the critical thinking skills test and the self-efficiency sclae in favor of the experimental group.
\end{abstract}

Keywords: Learning through projects, shared learning, social communication networks, critical thinking, self-efficiency.

*wd.o.1395@gmail.om 
الرقهي الخاص بهم، وتربط الهتعلمين بعضهم

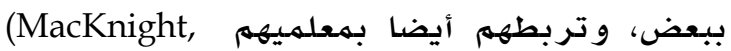
2000 ; Pape, 2010; Neville and Heavin, 2013) وقد أشارت دراسات عديدة إلى أهمية التعلهم التشاركي من خلال توظيف شبكات التواصل

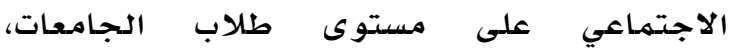
و توظيفها في تدريس الهقررات الجامعية

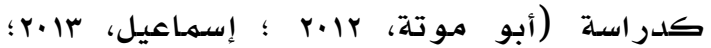
Thormann, Gable, Fidalgo ; Holmes, 2013, and Blakeslee, 2013 الجامعات ما لا يقل عن · ب دقيقة يوميا في التواصل عبر شبكات التواصل الاجتمـاعي Lovell) and Palmer, 2013) إلى تزويد المتعلمين بالمهارات التي تسـاعدهم

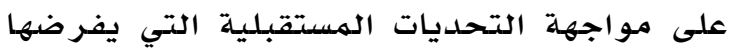
التعامل مـع التقنية الحديثة كمهارات التفكير

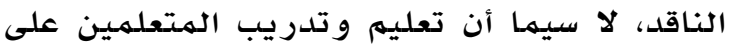
مـمارسدة مهارات التفكير الناقد يعد من أكبر الكبر التحديات التي تواجه التعليه الجامعي حاليا

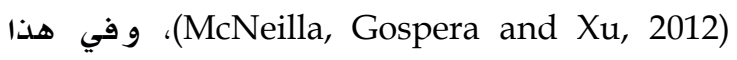

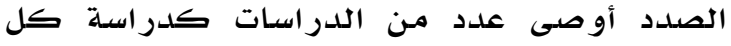

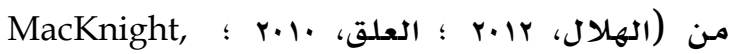

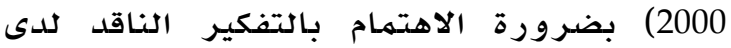

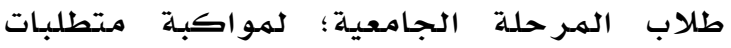

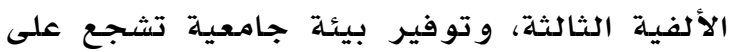
التفكير الناقد، وبضرورة تلدريب أعضاء هيئة التدريس بالجامعات على استخدام أسلدوب التعلهم الإلكترووني و مستحدثاته بشكل دوري لتتمية مهارات التفكير الناقد. وقد ظهر العديد من التعريفات للتفكير الناقد بسبب كثرة وجهات النظر و النظريات الكثيرة التي تناولته، وومن هذه التعريفات تعريف جون ديوي (John Dewey) و يعد مـن المححاو لات الأو لى في تعريفه إذ عرفه بأنه تفكير تأملي يرتبط بالقدرة على النشاط و المثثابرة، وهو تفكير حلذر يتناو ل دراسـة وتحليل المعتقدات، ووما هو متوقع من المعارف استنادا إلى خلفية حقيقية تلدعمها القدرة على الاستتنتاج (Fisher, 2001)، كما يعرف فئه بأنه عملية استخدام المنطق للتمييز بين العبارات
تتعامل الجامعات اليوم مـع جيل جلديد يسمى "الطلاب الرقميين" يتطلب منها إيجاد ثقافة و بيئة تعلم تدفع نحو تعزيز مشاركة الطالب،

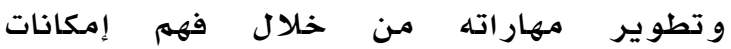

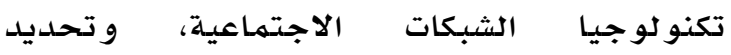
احتياجاتهم من مـاجياتلات استخدامها، و توقعاتهم

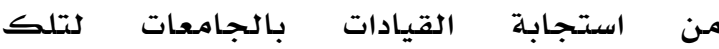
الاحتياجات.

ففي ظل تطور التقنيـات الحديثة أصبـحت الحاجة ملحة إلى تقنيات تربوية جديدة توجه مسار إعداد الطلاب بكلية التربية في مجتمه المعرفة؛ ونتيجة لذلك ظهر كثير من التقنيات التربوية الجديدة بما فيها التعلهم التشاركي (إسهماعيل،

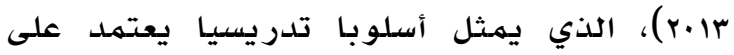
الهناقشة في الآراء والأفكار؛ الأمر الذي يضع

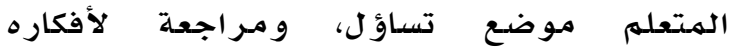

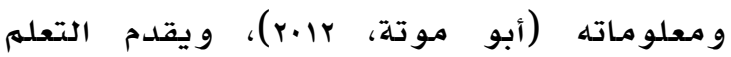
التشاركي عبر الويب خبرات تعليمية مهمهة، من خلال إتاحة الفرصة للمتعلهم لاستخدام أساليب

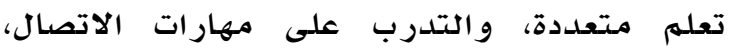
وكذلك تقسيم العمل، و المشاركة في الأفكار. وقد قدمت الويب (r,r) بعض التطبيقات التي

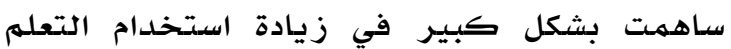

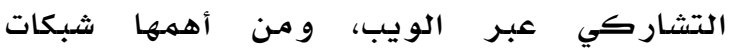
التواصل الاجتهاعي، والتي تعد الأكثر انتشارا على شبكة الإنتر نت، إذ تمثل أداة تعليمية متميزة إديزة إذا تم استخدامها بفعالية، كما أن لها تأثيرا

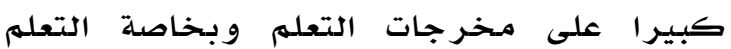
بالفريق (Kima, Hong, Bonk and Lim, 2011).

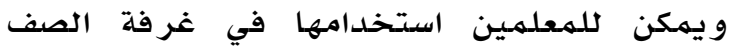
و بخاصة في التعليم الجامعي، من أجل تحسين

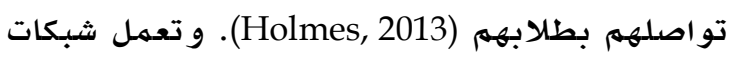
التواصل الاجتماعي على إكساب المتعلمين مهارات التعلم مدى الحياة، كها تتيح لهم فر صدة

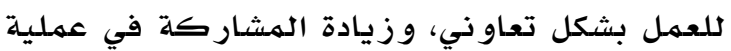
التعله، وتدعم وتعزز كذلك مهارات التفكير

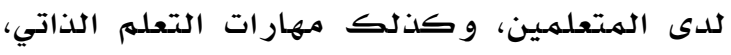

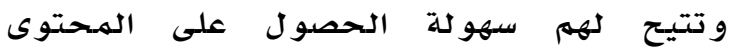
المعرفي بحرية أكبر، وكذلك بناء المحتوى 
واستهدفت الدراسلة التعرف على أثر التعلهم الإلكترووني في تنمية التفكير الناقد ، و تكونت

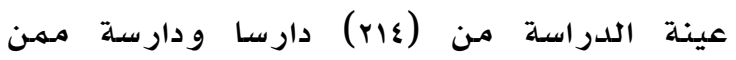
سجلوا في أحد أشكال التعلهم الإنكتروني، وقدل

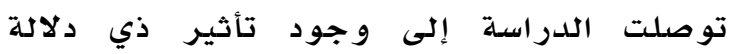

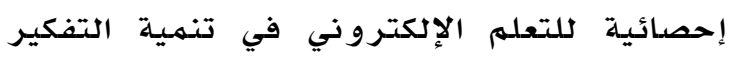

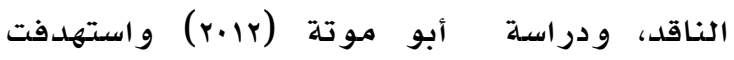
التعرف على فاعلية نظام تعليهم إلكتروني قائم

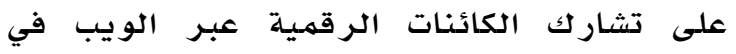
تنهية التحصيل والتفكير الناقد ، وتكونت التهيل عينة

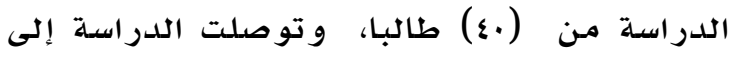
وجود فروق دالة إحصائيا عند مستوى (ه.,.•)

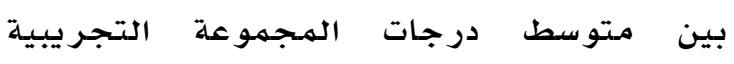

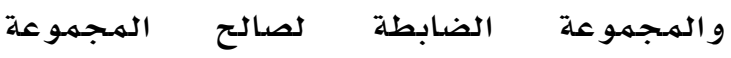
التجريبية في التحصيل والتفكير الناقد، و وراسـة

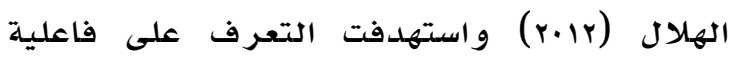

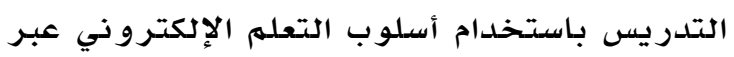

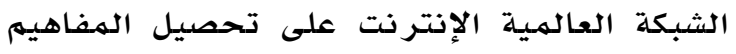

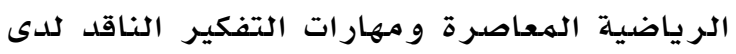

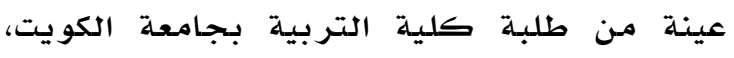
مقار نة بالطريقة التقيلدية المعتاد استخدامها في تلدريس المقرر بالجامعة، و وتكونت عينة الدراسـة

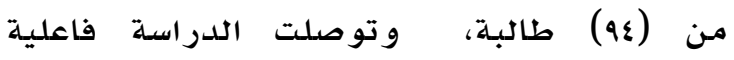
التدريس باستخدام أسلوب التعلهم الإلكترو ني عبر

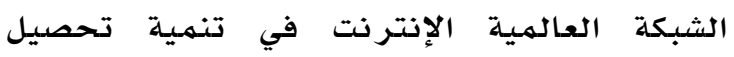

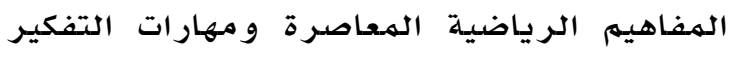

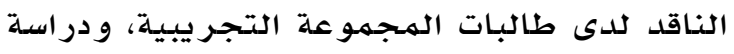

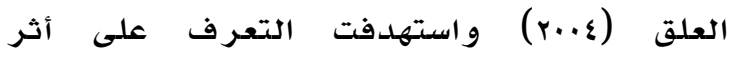
استخدام نموذج هاريس في تصميه الأنشطة

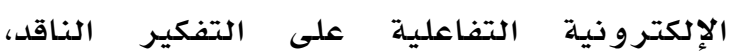

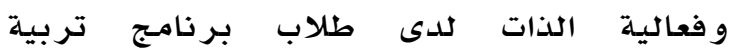
المـوهو بين بجامعـة الخليج العربي. و وتكونت عينة

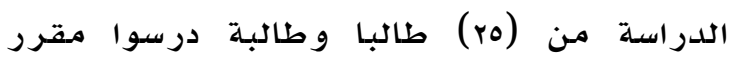

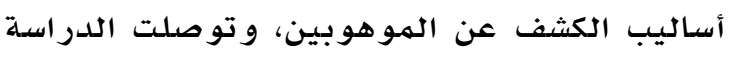
إلى عدم فاعلية توظيف أدوات و سـائل التعلهم الإلكترووني في تنمية التفكير الناقد؛ إلا أنها ثبت فاعليتها في تنهية فاعلية الذات.

يتضح من العرض السـابق للدراسات السابقة تشديدها على أهمية توظيف التعليهم الإلكتروني

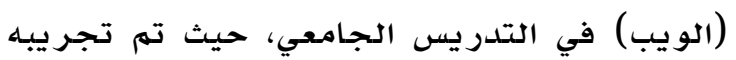

الصحيحة وغير الصحيحة التي يسهعها الشخص

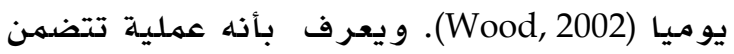

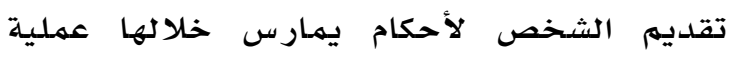
التفسير و التحليل والتقويم والاستدلال، ويقدم

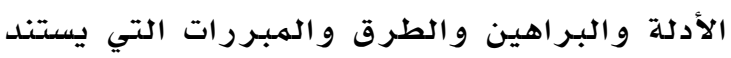
إليها في حكمه (Facione, 2011).

و يؤدي التفكير الناقد دورا في تحسين قدرة

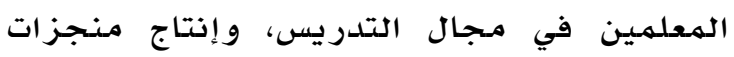
عملية قيهمة و مسؤو لة، وتحسين تحصيل الهتعلهم في المواد الدراسية المختلفة، و ويشجع المتعلهم

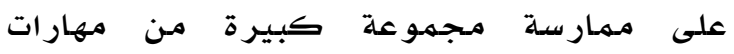

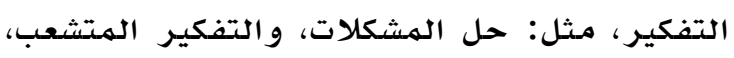

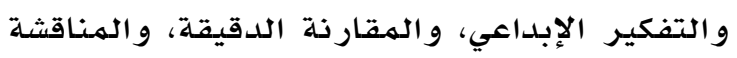

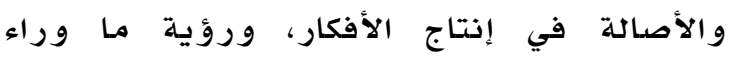

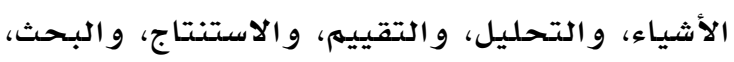

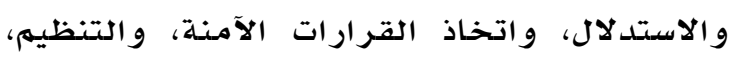

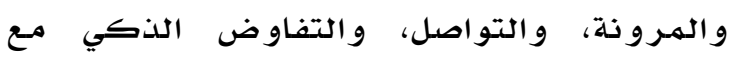

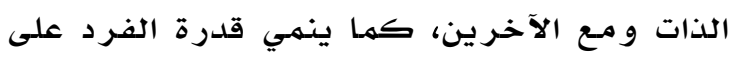

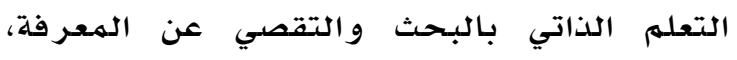
كذلك يؤدي إلى قيام المتعلهم بمر اقبة تفكيره

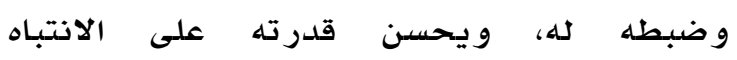
و الملاحظة، كها يمكن الشخص من تقديهم وجهة نظره الخاصة بشكل أكثر سهولة (أبو جادو الهاد

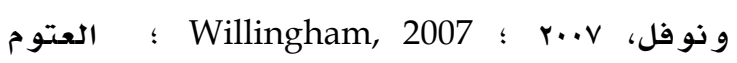

$$
\text { و آخرون، r...v }
$$

ويتأثر التفكير الناقد بعدد من المتغيرات الههمهة، و منها فاعلية الذات، بحيث يمكن أن يكون مساعدا

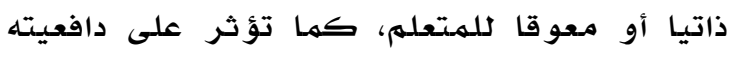

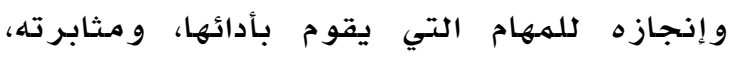

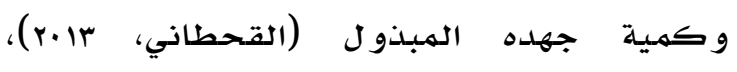

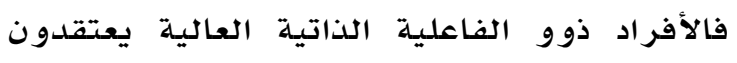

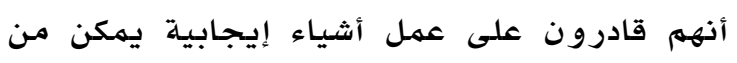
خلالها تغيير واقع البيئة التي يعيشون فيها، أما

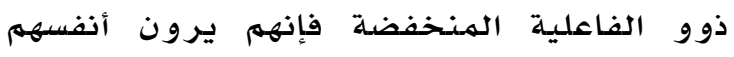
عاجزين عن إحداث سلوك له آثاره و ونتائجه

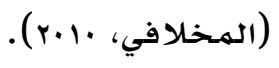

وقد تناول عدد مححدود من الدراسات السابقة البحث في فاعلية بعض أدوات وووسائل التعلهم

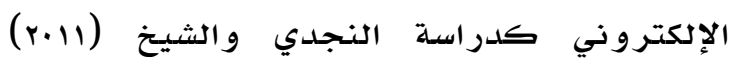


زالت تلك المتطلبات والتحديات جميعا تلازم

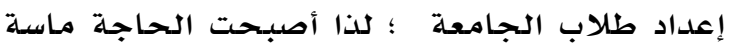
إلى تطوير أنظمهة التعليه اعتمهادا على التقنيات

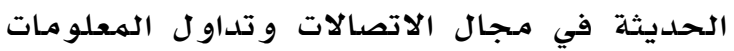
بما ينهي قدرة الهتعلهين على مواجهة التحديات المستقبلية من خلال مهارات التفكير الهختلفة

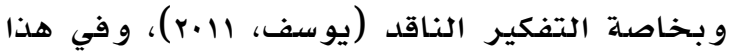

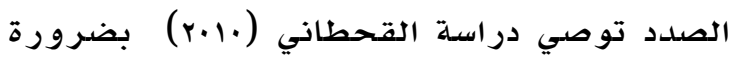
الاهتمام بالتفكير الناقد لدى طلاب الدر الهر حلدة الجامعية لمواكبة متطلبات الألفية الثالثة، و توفير بيئة جامعية تشجع على التفكير الناقد ، وبضرورة استمر ارية استخدام و مهمارسـة التفكير

$$
\text { الناقد في التعليم الجـامعي. }
$$

توصلت دراسلة (الشايع وبطيشة، rا+r) إلى أن طالبات جامعة الأميرة نورة يستخدمن شبكات

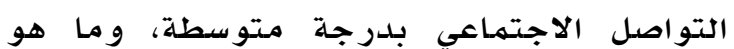
موجود على شبكة الإنتر نت من اختر اعات ونتائج تجارب و أبحاث علميلة قابلة لتغيير و وتحتهل

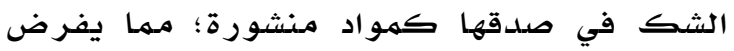

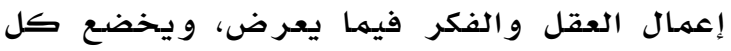
ذلك للفحص والتمحيص، مهما يتطلب مهمارسة التفكير الناقد. وفي هذا الصدد توصي دراسـة

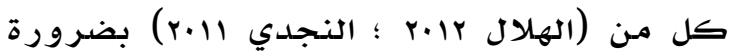

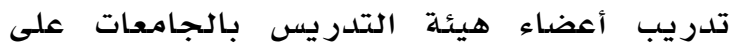
استخدام أسلوب التعلم الإلكتروني و مستحدثاته بشكل دوري لتنمية مهارات التفكير الناقد، و بضرورة إجراء الهـزيد من الدراسـات والبحوث لاكتشاف الهزيد من العلاقات بين التفكير الناقد اهدراء و التعلهم الإلكتروني، واقتراح نهاذج إضافية من التطبيقات.

تتطلب دراسة مقرر التعلهم بالمشروعات التعاون و المشاركة و التواصل المستمرر بين الطالبات

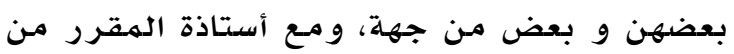
جهة أخرى خلال مر احل الهشروع ؛ إلا أن زمن

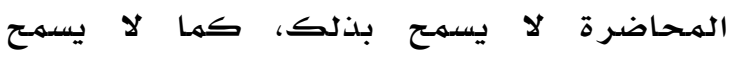

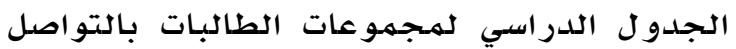
و المناقشة في الخطوات التي يتطلبها إنجاز

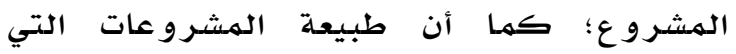
تتناو لها الطالبات تتطلب مشاركة الجمهور في الجئ
في معظم الدراسات على طلاب المـرحلة

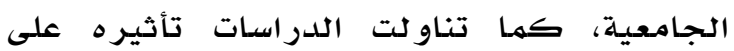
تنمية التفكير الناقد وفاعلية الذات، و واتضح تفاوت نتائج توظيف التعليهم الإلكتروني (الويب) في تنمية التفكير الناقد، في حين أثبتت فاعليته في تنهمية فاعلية الذات. كما له تتناول

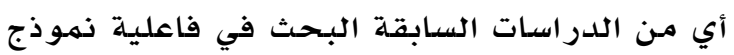

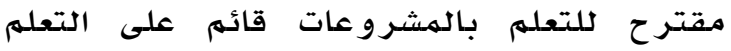
التشاركي باستخدام شبكات التواصل الاجتهاعي في تنمية مهارات التفكير الناقد وفاعلية الذات . مشكلة الدراسة هنالك عدد من المبررات دعت إلى إجراء الدراسـة الحالية، يمكن عر ضها فيما يلي: أكدت دراسات كثيرة على أهمية التعلم التشاركي من خلال توظيف شبكات التواصل

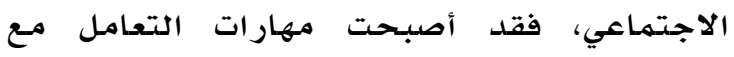
تطبيقات الإنترنت هدفا أساسيا تسعى إليه كل

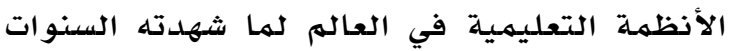

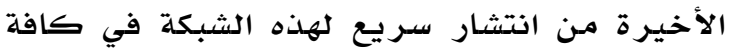

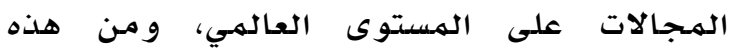

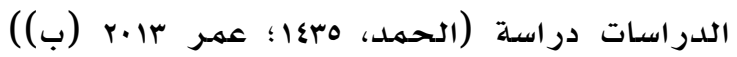
وشددت على ضرورة الاستفادة مـن شبكات التواصل الاجتماعي على مستوى طلاب الجامعة، وتوظيفها في تدريس المقررات الجامعية، كما

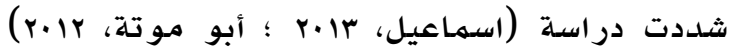
على أهمية التعلهم التشاركي القائم على شبكات

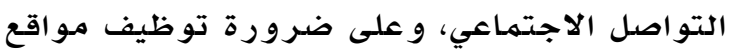

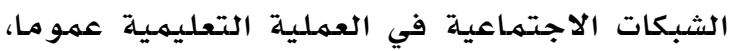
و في تطبيق التعلهم التشاركي وبخاصدة داخل

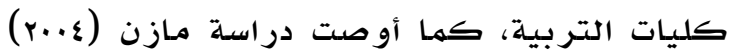

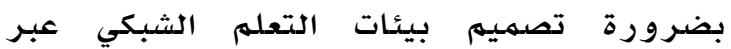
الإنترنت والاستفادة منها في تطوير التعليم الجـامعي.

يشهد العالم اليوم اهتماما بالغا في مـجال إعداد

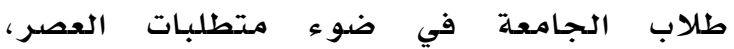

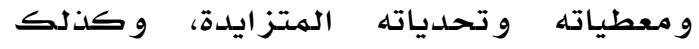

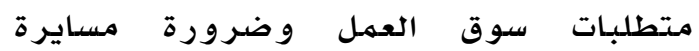

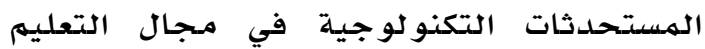
والتمكن من توظيفها على نحو دقيق و فعال، و ما 


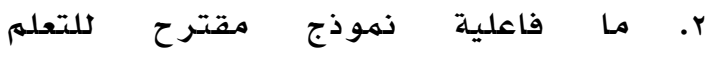
بالهشروعات قائم على التعلهم التشاركي

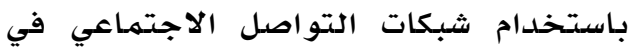

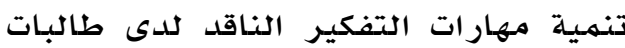
جامعة الأميرة نورة بنت عبد التهيه الرحمن؟

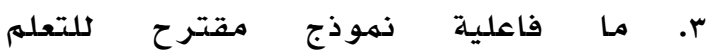
بالمشروعات قائم على التعلهم التشاركي باستخدام شبكات التواصل الاجتماعي في في فئري

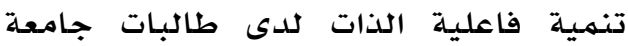
الأميرة نورة بنت عبد الرحمن؟

أهداف الدراسة

تستهدف الدر اسـة الحالية:

ا. اقتراح نموذج للتعلم بالمشروعات قائم

على التعلهم التشاركي باستخخدام شبكات بهات التو اصل الاجتماعي.

r. تقصي فاعلية نهوذج مقترح قائم على التى

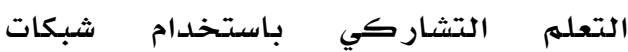
التواصل الاجتماعي في ت فنمية مهارات التفكير الناقد لدى طالبـات جامعة الأميرة نورة بنت عبد الرحمن. r. تقصي فاعلية نموذج مقترح قائم على التص التعلم التشاركي باستخدام شبكات التواصل الاجتماعي في تنمية فاعلية الذات لدى طالبات جامعة الأميرة نورة بنت عبد لديد

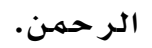
أهمية الدراسة

1. تنسجم الدراسة الحالية مـع التوجهات التربوية الحديثة الداعية إلى الاهتمام الدام الديه

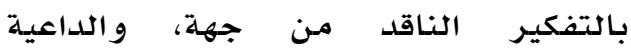
كلاهتمام بتوظيف شبكات التواصل

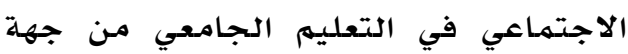

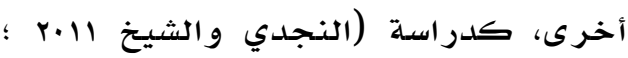

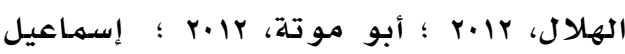
2013، Holmes ؛ r.lr.

Thorman et al., 2013)

r. تستمدد الدراسـة الحالية أهميتها من أنها

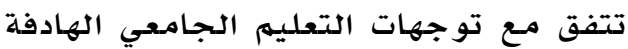

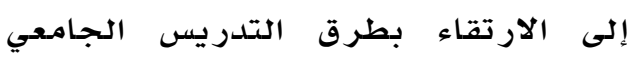

(الاستفتاءات الإلكتروونية-والإجابة عن بعض

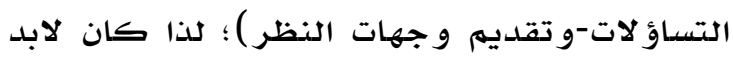
من توظيف بعض شبكات التواصل الاجتماعي مثل

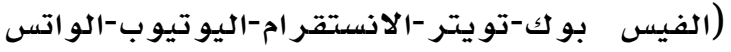

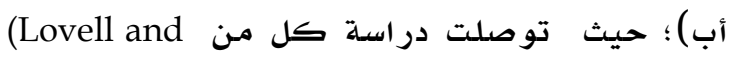

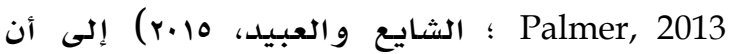
شبكات التواصل الاجتماعي هي الوسيلة المفضلة

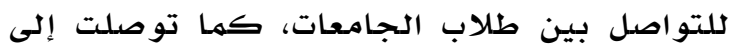
إجماع المتعلمين على مناسبـة شبكات التواصل

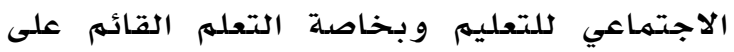

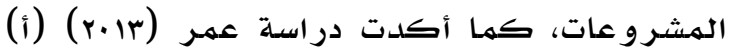
على ضرورة استخدام وتطبيق استراتيجيات

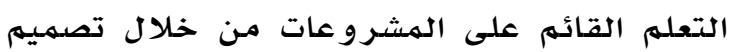

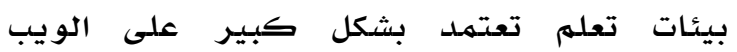
و تطبيقاته الاجتمهاعية.

بالنظر إلى الدور الذي تلعبه فاعلية الذات في أنماط التفكير ومنها التفكير الناقد، كان الدور لابد

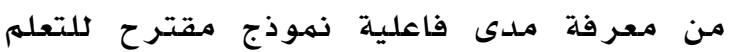

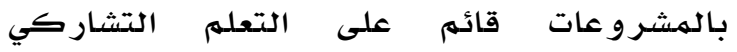
باستخدام شبكات التواصل الاجتمهاعي في تنمئم فاعلية الذات لدى الطالبـات.

و في ضوء ما تقدم ووما أثبتته وأوصت بـ أبه

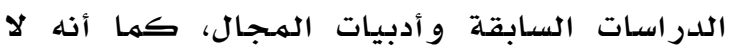

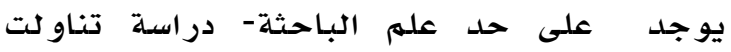
فاعلية نموذج مقترح للتعلم بالمشروعات قائمر على التعلهم التشاركي باستخدام شبكات التواصل

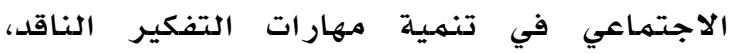

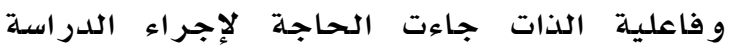

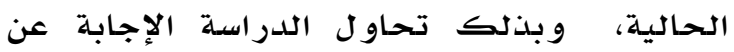
السؤال الرئيس التالي: ما فاعلية نهوذذج مقتروح

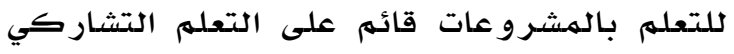
باستخدام شبكات التواصل الاجتماعي في تنميلة

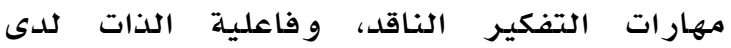

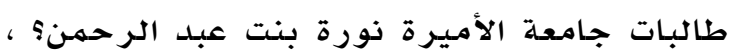
ويتفرع من هذا السؤال الأسئلة الفر عية التالية: ا . ما النموذج المقترح للتعلهم بالمشروعات قائم على التعلهم التشـاركي بـاستخدام شبكات التو اصل الاجتهـاعي؟ 
و فاعلية الذات للدى طالبات جامعة الأميرة ذورة بنت عبد الرحمن، ويتم تحديد الأثر إحصائيا

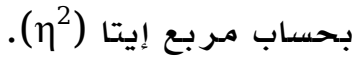

التعلم بالمشروعات: استراتيجية تعلهم مرتكزة

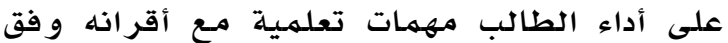

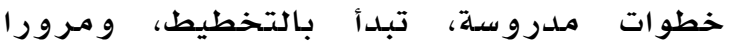

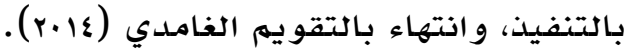
ويعرف إجرائيا بانه: إحدى طرق التعليم والتعلم

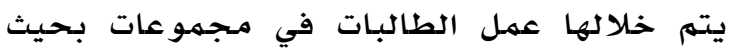
يشكلن فرق عمل تتولى اختيار فكرة المشروع و التخطيط له مـن خلال المشاركة بعضهن بعضا لهض و مـع أستاذة المقرر، وومن ثم تنفيذها، و بعد الانتهاء من إنجاز المشروع يتهم تقييهمه من قبل

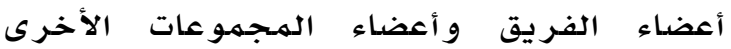

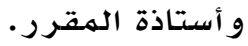

التعلم التشاركي: هو شكل من أشكال تنظيم

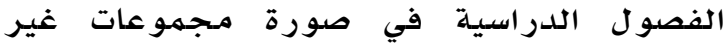

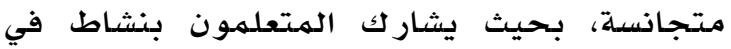
إنجاز مهام التعلهم بتوجيه وإرشاد من المعلهم (Duze, 2010

شبكات التواصل الاجتماعي: وسيلة يمكن من

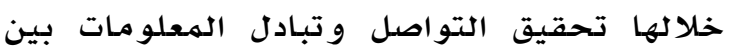
الأفر اد و الملفات و الرووابط و المحادثات و غيرها من الروابط، و تحقيق عملية التواصل الاجتماعي

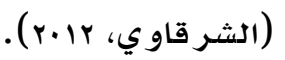

التعريف الإجرائي: وسيلة يمكن مـن خلالها التواصل وتبادل المعلومات ووجهات النظر بين الطالبات بعضهن و بعض و أستاذة الهقرر و و الجمهور الخارجي في مقرر التعلهم بالمشرو عات

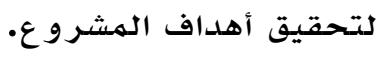

ويعرف التعلم التشاركي باستخدام شبكات التواصل الاجتماعي إجرائيا بانه: طريقة تعلهم تفاعلية تتضمن قيام الطالبـات باختيار فكرة المشروع و التخطيط لها من خلال المشاركة الهـ

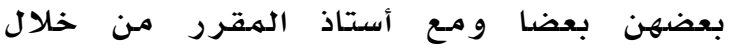

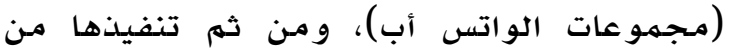

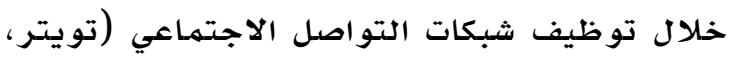

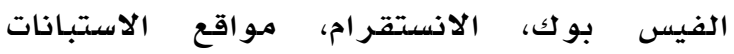

و بخاصلة أنها تعنى بتوظيف التعلهم

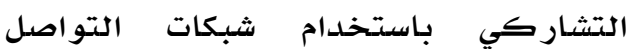
الاجتماعي والذي يعد من أهم الأساليب

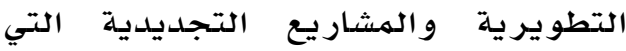
تسعى الجامعات إلى تبنيها.

r. تدريب الطالبات على مهارسة مهارات

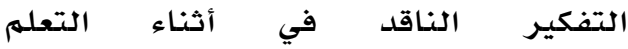
بالهشروعات خلال التعلهم التشاركي باستخدام شبكات التواصل الاجتماعي؛ مـما قد يفيد في اكسابهن القدرة على التعامل مـع متطلبات التقنية المستقبلية. ع. من المتوقع لنتائج هذه الدراسة أن تكون

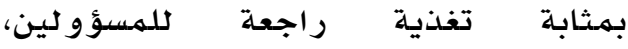

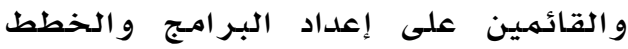

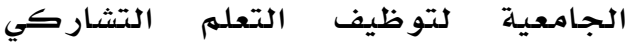

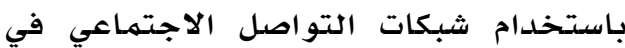
التعليهم الجامعي.

•. تسهم الدراسـة في تقديه مقياس لفاعلية الذات يمكن استخدامـه في قياس فاعلية الدات للدى المتعلمين. فروض الدراسة ا. لا يوجد فرق ذو دلالة إحصائية (عند

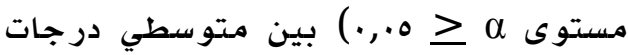

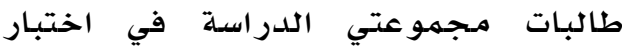

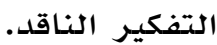
r. لا يوجد فرق ذو دلالة إحصائية (عند

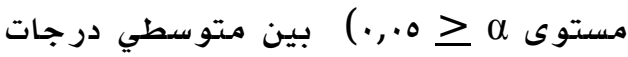

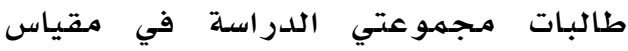

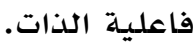

مصطلحات الدراسة الفاعلية Effectivenss: "يعبر مصطلح الفاعلية بالدراسات التربوية التجريبية عن مدى الأثر الذي يمكن أن تحدثه المعالجة التجريبية

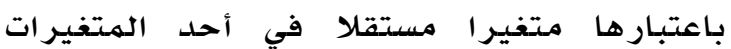
التابعة" (علي، 199V، IV). و تعرف إجرائيا بأها: الأثر الذي يمكن أن يحدثه النـموذج الهقتر ح في تنهمية مهارات التفكير الناقد 
مجتمـع وعينة الدراسة: تكون مجتهـع الدراسـة

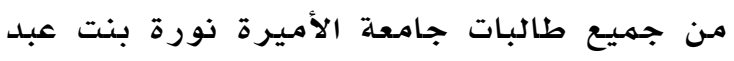

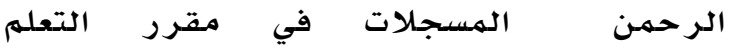
بالمشرو عات و بلغ عددهن (070) طالبة، في حين

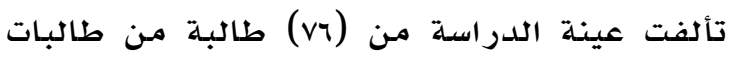

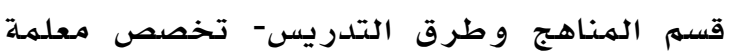
صفوف أولية، تم اختيارها بالطريقة العشوائية

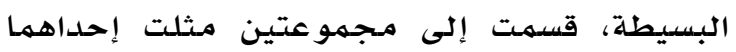

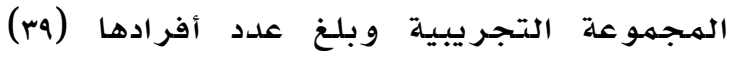

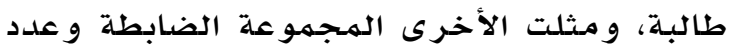
أفر ادها(rv) طالبـة.

\section{الإعداد لتجربة الدراسة}

إعداد النموذج المقترح: الثددت الدر اسـات التربوية على أهمية طريقة التعلهم بالمشرو عات

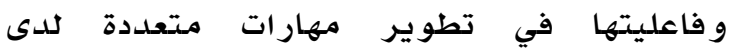

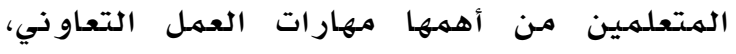

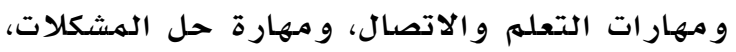

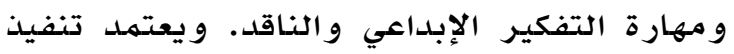

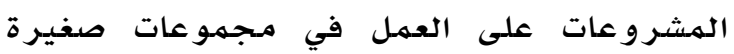
يتبادل فيها الطلاب المعلومات والآراء وتمكنهمه

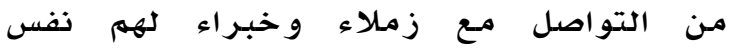

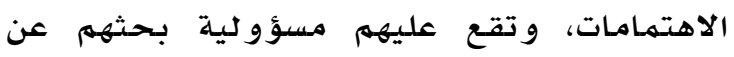

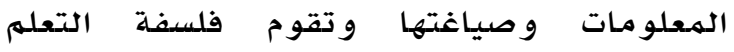
بالمشاريع على العديد من المنطلقات التربوية ولهية

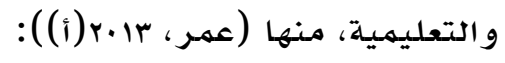

النظرية البنائية: وهي فلسفة تعليمية تقوم على

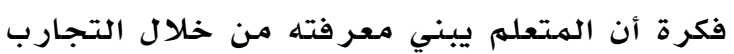

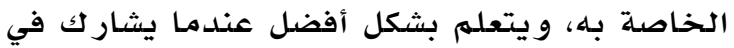

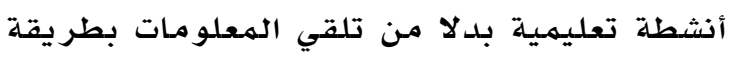

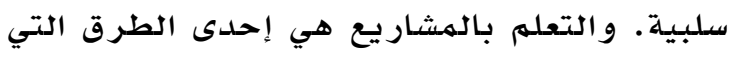

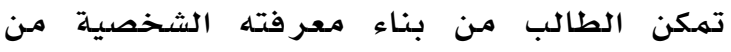
خلال المهمارسة، و معالجة مشكلات حقيقية.

نظرية جاردنر للذكاءات المتعددة: وهي أن كل شخص لديه أنواع مختلفة من الذهاءودات، مثل

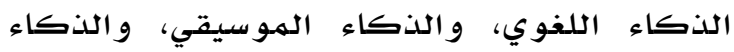

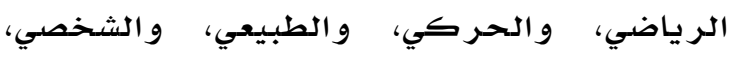

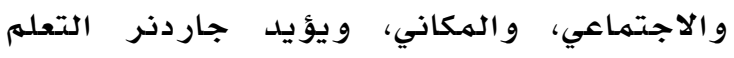

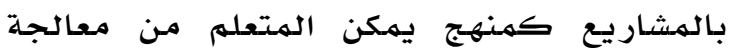

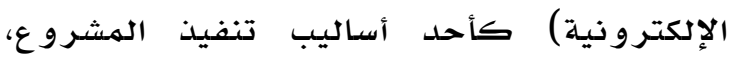

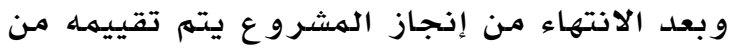
قبل أستاذة الهقرر و أعضاء الهـجمو عات الأخرى الهر. التفكير الناقد: تفكير تأملي استدلادي يشدد على اتخاذ قرار ما بشأن ما يعتقده الشخص أو يفعلد .(Dunn, Rakes, and Rakes, 2014)

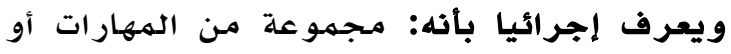

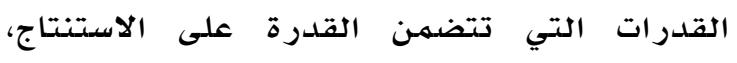

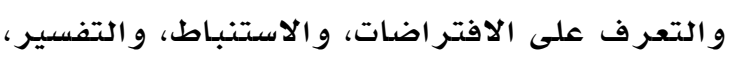
وتقويم الحجج، ويقاس من خلال أداء الطالبات

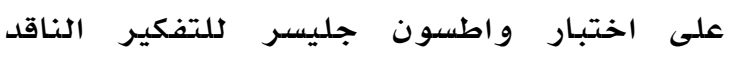
(الصورة المختصرة (WGCT-FS).

فعالية الذات: تعرف بأنها معتقدات الفرد في

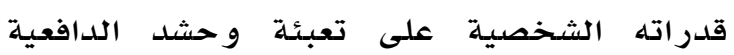

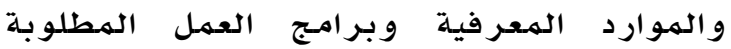

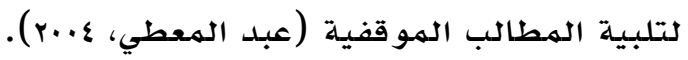
وتعرف إجرائيا بانها: تصور الطالبة لقدراتها الذاتية التي يتطلبها تحقيق أهداف المشروع. حدود الدراسة

ا. التطبيق بكلية التربية بجامعة الأميرة

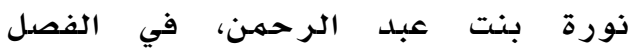

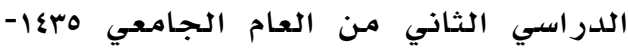
דr|l اهـ.

r. قياس مهارات التفكير الناقد باستخدام

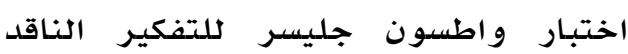

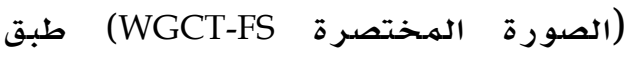
قبليا و بعديا على مجموروتي الدر اسـة. r. قياس فاعلية الذات باستخدام مقياس فاعلية الذات من إعداد الباحثة، طبق قبليا و بعديا على مـجمـوعتي الدر اسلة.

\section{منهج الدراسة و إجراءاتها}

منهج الدراسة: استخدم المنهج التجريبي في

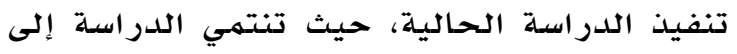

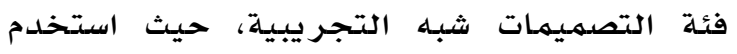

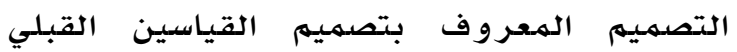

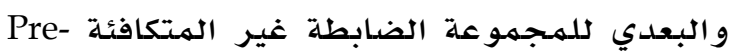
.Posttest Nonequivalent Control Group 


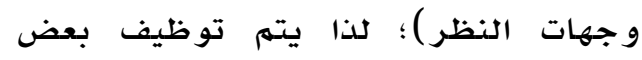

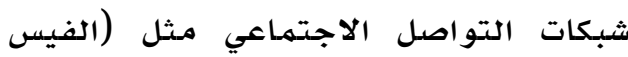

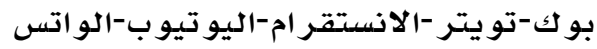

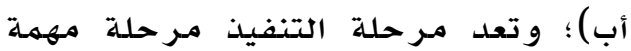
في طريقة المشروع حيث تهيئ الفرصة كل طالبة أن تكتسب الخبرات بطريقة

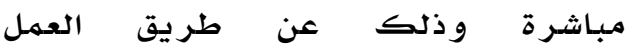

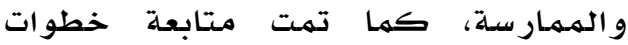
تنفيذ المشروع بشكل مستمر بين أعضاء

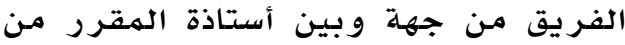

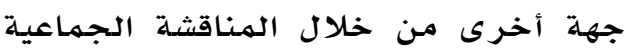

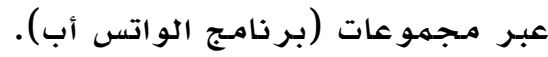
ع. تقويم المشروع: وفق النموذج المقترح

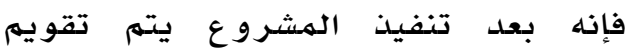
المشروع وذلك للوقوف على مدى تحقق أهداف المشروع. وقد تمدت عملية التقويم من خلال: عرض نتائج المشروع على أستاذة المقرر ومناقشتها معها من خلاتلال المثرو

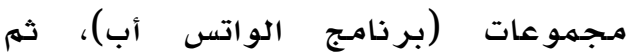

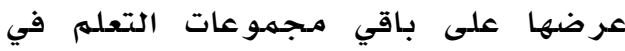
قاعة الدراسة؛ للوقوف على نقاط القاط القوة التي تحققت عند الطالبات ونقاط الضعف في المشروع أو التي لم تتحقق وذلك الكاط من أجل تلافيها عند القيام بمشاريع

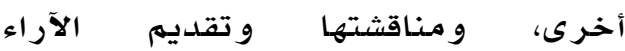
و المقتر حات. - مات و منات

و قد تم إعداد النموذج المقترح للتعلم التمانم

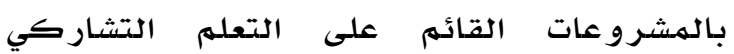

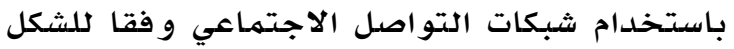
ا. وبهذا تمت الإجابة عن السؤال الأول من أسئلة التهاتئل

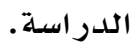

المشكلات والتحديات الحقيقية التي تنهي لديه ذكاءات متعددة.

التعلم التعاوني: وهي استر اتيجية تلدريسية يستخدمها المعله داخل الصف لتحقيق أهداف

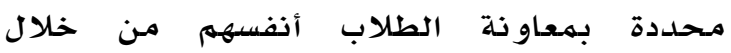
تعاونهم فيما بينهم في مجمو عات لكل عضو فيها

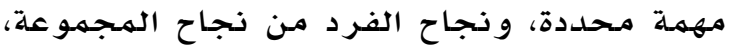
و يوفر التعلهم بالمشاريع بيئة تنهي لدى الطلاب

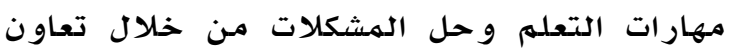
الطلاب لإكمال المشروع. و تتمثل خطوات التعلهم بالمشرو عات وفق النهوذذج المقتر ح بالخطوات التالية:

ا. اختيار المشروع: وهي خطوة مهمة جدا؛

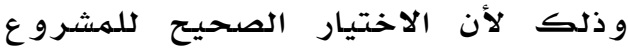
يساعد على تحقيق الهشروع و إنجازه. ووفق النموذج المقترح يتم اختيار

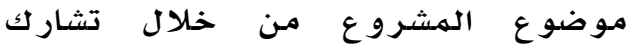

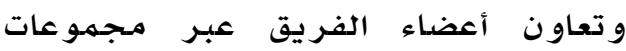

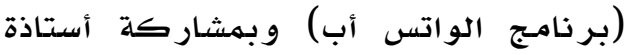
المقرر. - المر

r. وضع الخطة: حيث يتم في هذه الخطوة

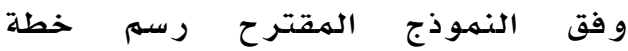

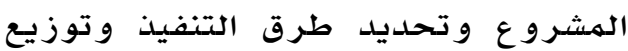
الهمهام بين الطالبات وومناقشتها بمشاركة أستاذة المقرر وإجراء أي تعديل عليها أو أو مهيل

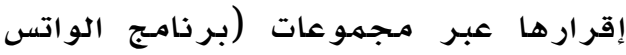
أب). و مشاركة الطالبات في وضعات الخطو الخطة

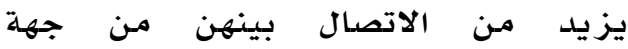
والطالبات و أستاذة الهقرر من جهة أخرى بحيث ينمسي المهار ات الاجتهماعية بينهن. r. تنفيذ المشروع: حيث تقوم كل طالبة في

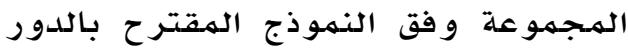

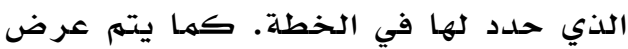

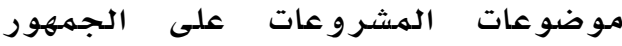
الخارجي إذ إن طبيعة المشروعات التي تناو لتها

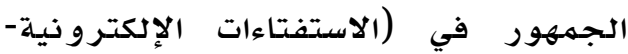

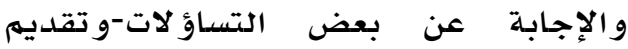




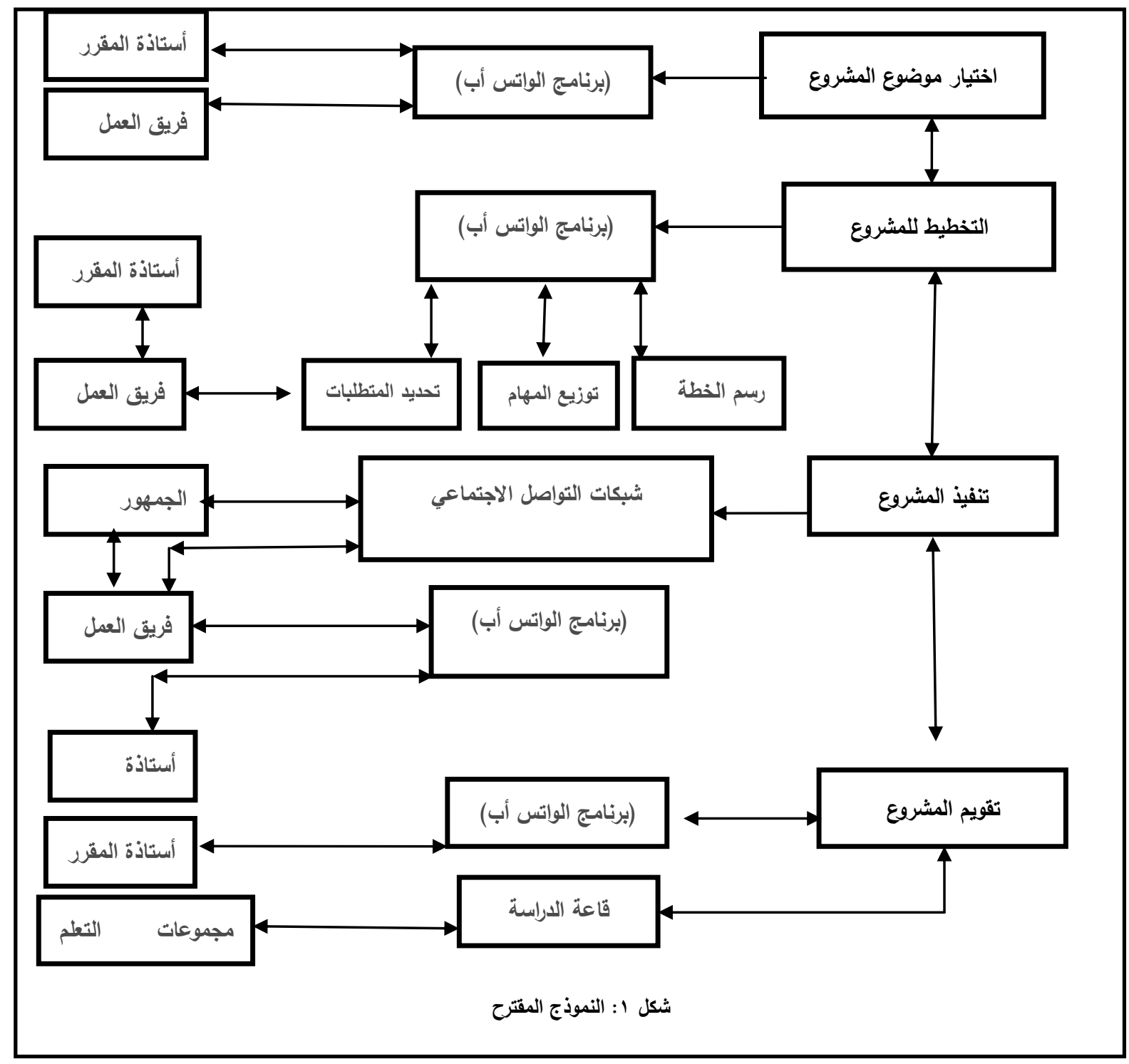

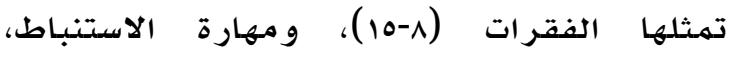

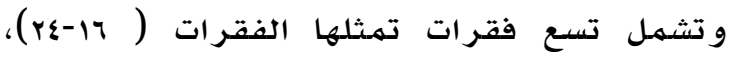

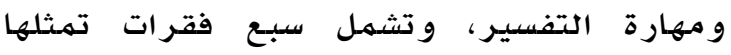

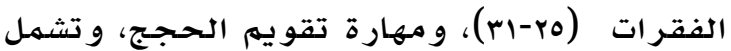

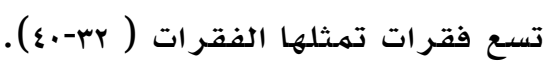
صدق وثبات اختبار مهارات التفكير الناقد: للتحقق من صدق الاختبار تم تطبيق الاختبار في وندار

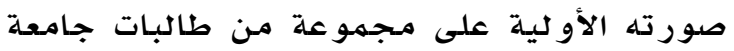

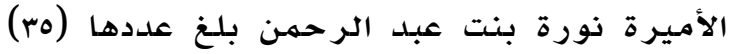
طالبة من خارج عينة الدراسة تمر اختيارها بالطريقة العشوائية البسيطة، وتم حساب صدق التابن

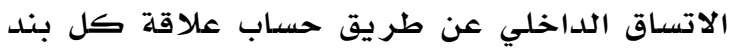
من بنود المقياس بالدرجة الكلية للمقياس كما كال

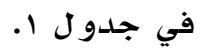

إعداد أدوات الدراسة اختبار التفكير الناقد: اقتصرت الدراسة الحالية

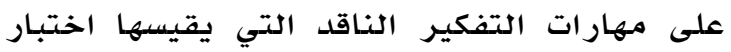
التفكير الناقد الذي و ضعهـ و اطسون 19 و وعدله جليسر واستقر بصورته النهائية في عام ع797.

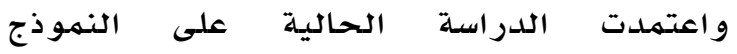

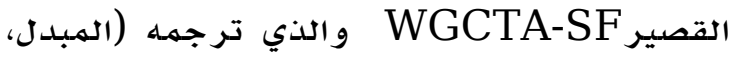

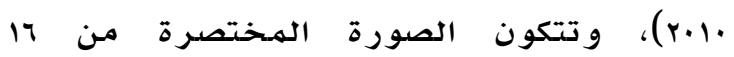

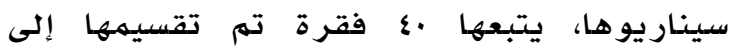

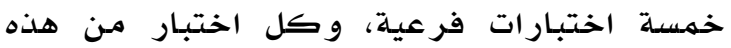

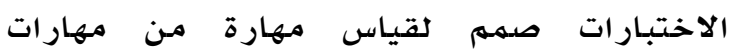
التفكير الناقد، وهي: مهارة الاستنتاج، وتشمل

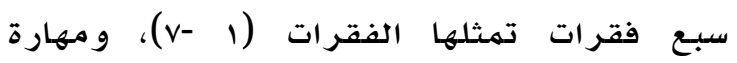

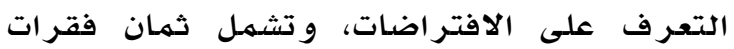


معاملات ارتباط بنود الاختبار بالارجة الكلية للمقياس

\begin{tabular}{|c|c|c|c|c|c|c|c|c|c|c|c|c|c|}
\hline المعامل & 5 & المعامل & 5 & المعامل & 5 & المعامل & 5 & المعامل & 5 & المعامل & م & المعامل & م \\
\hline$\cdot, \Gamma \leqslant$ & rv & $\cdot, 0 \leqslant$ & r & r & ro & $\cdot, \Gamma \wedge$ & 19 & דוז, & $1 \pi$ & r & v & $\cdot, \leqslant V$ & 1 \\
\hline$\cdot, r \cdot$ & rᄉ & . Or & rr & זr, & TT & $\cdot, \varepsilon$. & $r$. & $\cdot, \leqslant 9$ & $1 \varepsilon$ & $\cdot, 01$ & $\wedge$ & $.0 r$ & r \\
\hline r, or & rq & $\cdot, \Gamma$ & Tr & $\cdot, 00$ & TV & זr, & rI & $\cdot, \leqslant 1$ & 10 & $\cdot, 00$ & 9 & $.0 r$ & $r$ \\
\hline \multirow[t]{3}{*}{$\cdot, \mathrm{V} 0$} & $\varepsilon$. & $\cdot, \leqslant V$ & $r \varepsilon$ & . TO & YA & זT, & rr & $\cdot, 0 \leqslant$ & 17 & $\cdot, 01$ & 1. & $\cdot, \varepsilon$. & $\varepsilon$ \\
\hline & & $\cdot, r \cdot$ & ro & $\cdot, \leqslant 9$ & rq & $\cdot, \varepsilon \varepsilon$ & rr & $\cdot, \sum r$ & IV & • & 11 & $\cdot, \varepsilon r$ & 0 \\
\hline & & $\cdot, \vee \vee$ & דr & $\cdot, O \mathrm{~V}$ & $r$. & $\cdot, r V$ & $r \leq$ & $\cdot, 0 \leqslant$ & 11 & $\cdot, 01$ & IT & $\cdot, \varepsilon \varepsilon$ & 7 \\
\hline
\end{tabular}

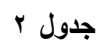

معاملات ارتباط بنود مقياس فاعلية الذات بالدرجة الكلية للمقياس

\begin{tabular}{|c|c|c|c|c|c|c|c|c|c|c|c|c|c|}
\hline المعامل & 5 & المعامل & 5 & المعامل & 5 & المعامل & م & المعامل & 5 & المعامل & ? & المعامل & م \\
\hline$\cdot, r$ & rv & . & r & דז,. & ro &., 19 & 19 & $\cdot, \leqslant 7$ & $\pi$ & $\cdot, \Gamma \wedge$ & V & $\cdot, Y_{I}$ & 1 \\
\hline r & rᄉ & $\cdot, 17$ & r & . & ru & . & $r$. & $\cdot, r_{l}$ & $1 \varepsilon$ & זr, & $\wedge$ & • & $r$ \\
\hline., 01 & rq & צr, & זr &., 09 & TV & .,$\leqslant Y$ & r) & $\cdot, \varepsilon r$ & 10 & $\cdot, \varepsilon 1$ & 9 & • & $r$ \\
\hline \multirow[t]{3}{*}{$\cdot, 0 \leqslant$} & $\varepsilon$. & • & $r \varepsilon$ & שT, & rA & 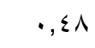 & Tr & $\cdot, 99$ & 17 & سו, & 1. & •,,$\leqslant 7$ & $\varepsilon$ \\
\hline & & • • & ro & $\cdot, r \cdot$ & rq & $\cdot, 1 Y$ & r & 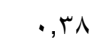 & IV & $\cdot, r$. & 11 & זr, & 。 \\
\hline & & $\cdot, r$. & ד r & ع & r. & $\cdot, r V$ & $r \varepsilon$ & • & 11 & $\cdot, \Gamma_{1}$ & Ir & $\cdot, r$. & 7 \\
\hline
\end{tabular}

r. صياغة مفردات الهقياس: تكـوّن الهقيـاس

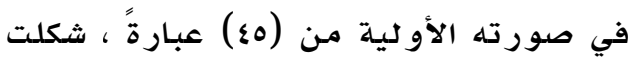

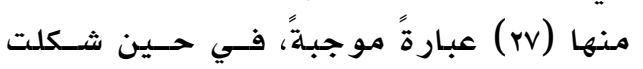

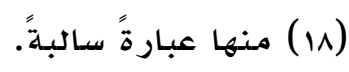

r. صدق المقياس: أمكن التحقـقُ مــن صــدق

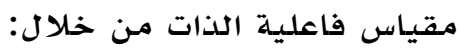

الصدق الظاهري: عرض المقياس في

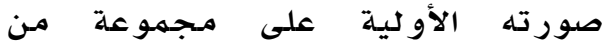

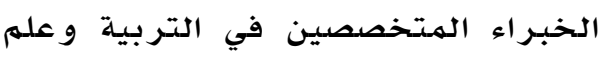
النفس لهعرفة آرائهم من حيث: وضوح

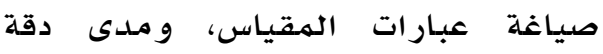

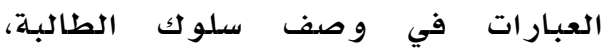

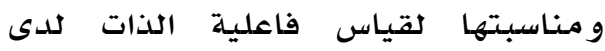

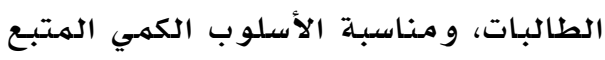

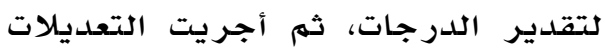

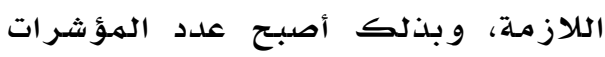

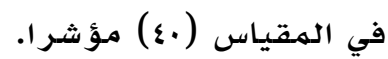
صدق الاتســاق الــداخليّ: طُبــق مقيـاسُ

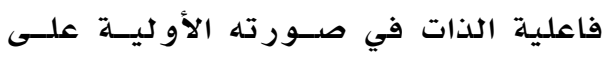

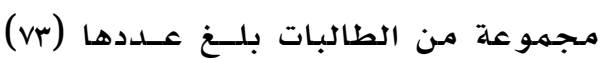

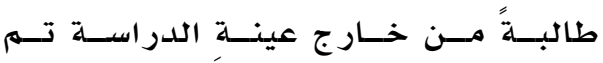
اختيارُها بالطريقة العشــوائية البسـيطة،
يتضح من جدول | أن معامل صدق الاتساق

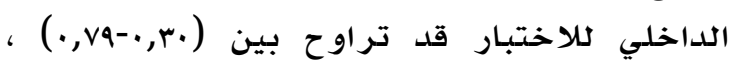
وجميعها دالة عند مستوى (

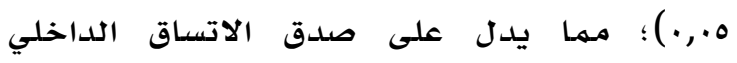
كلاختبار . ثبـات الاختبــار : تـهم حســاب معامسل ثبـات ألفــا

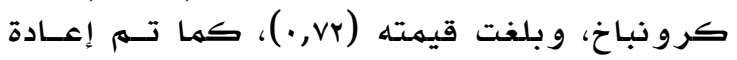
تطبيق الاختبار وحســاب معامـل الارتبـاط بــين

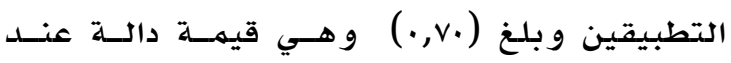

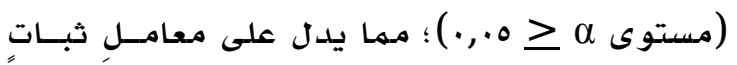
مناسب. إعداد مقياس فاعلية الذات: تم الاطلاع على بعض

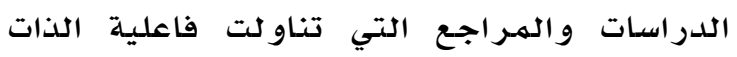
مثل (Bandura, 200 ؛ Brown, 2011 ؛ واجع القر يشي، ع) لإعداد مقياس فاعلية الذات، وذلك وفتا

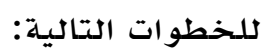
1. تحديد الهدف من الهقيـاس: وهـو قيـاس

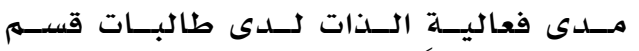

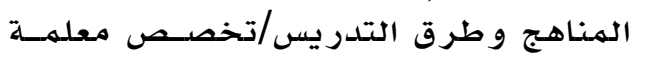
صفوف أولية. 
الهقتــر ح، ودرسـت المهجموعـة الضــابطة

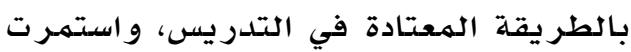

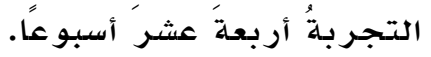

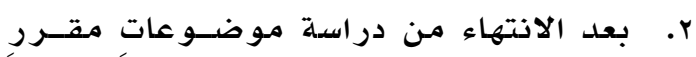

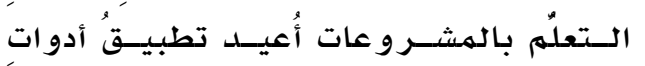

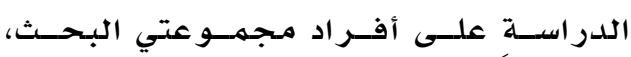
وجُمعت البيانات تمهيدًا لتحليلها إحصائيًا.

\section{عرض نتائج الدراسة وتفسيرها}

للتحقق مـن صحسة الفروض أسـتخدم اختبـار

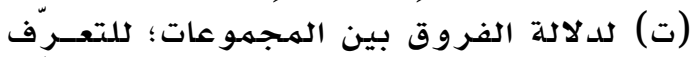

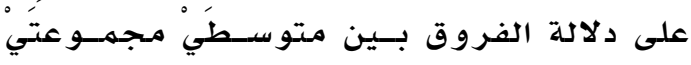

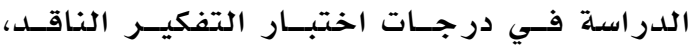

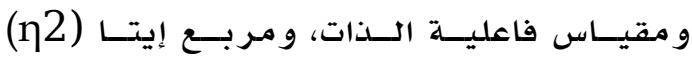

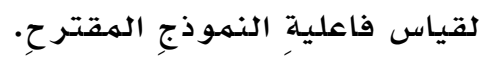

اختبار صحة الفرض الأول، وينصّ على أنه: لا

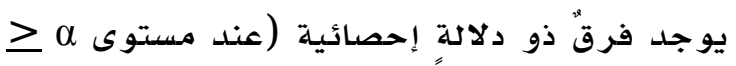

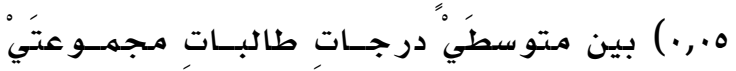
الدراسـة في اختبـار التفكير الناقد. جدول ؛

اختبار (ت) لالالة الفروق بين متوسطي درجات طالبات مجموعتي

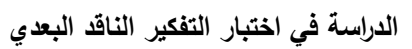

\begin{tabular}{|c|c|c|c|c|c|}
\hline الدلالة & قيمة ت & الالتحراف & الحسابي & العدد & المجموعات \\
\hline \multirow{2}{*}{$\cdot, \cdot r$} & \multirow{2}{*}{ r, } & $r, v$. & $19,9$. & rq & التجريبية \\
\hline & & $r, q 1$ & $1 V, 17$ & rv & الضابطة \\
\hline
\end{tabular}

يتضح من جدول ع أن قيممة (ت) دالة إحصائيا

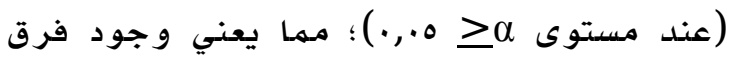
ذي دلالة بين مجموعتي الدراسة، وذلك لصدالح

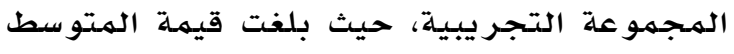

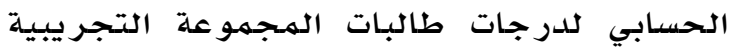

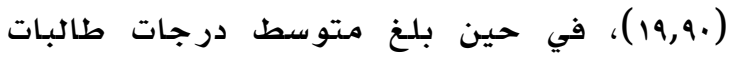
المجمو عة الضابطة (1V,17).

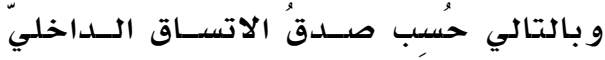

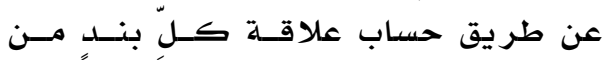
بنود المقياس بالدرجة الكلية للمقيـاس،

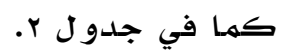

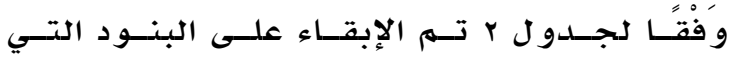

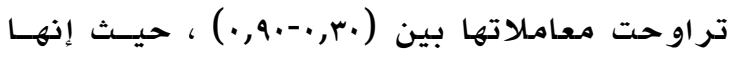

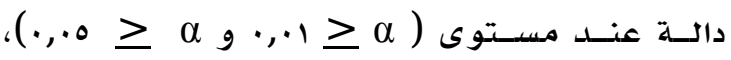
في حين حذفت البنود التي بلـغ معامـل ارتبـاطهـا

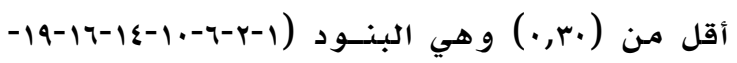
. (rr-rq

ا. ثبات المقياس: أمكنَ التحققٍ مـن ثبـات

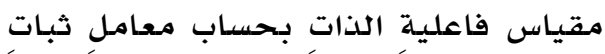
ألفا كرونباخ لأبعاد المقياس، وقدد بلغت

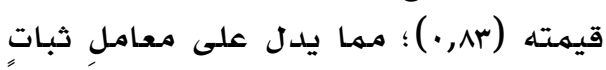
مناسب.

r. الصورة النهائية للمقياس: بلـغ عسددُ بنــودٍ المقياس في صورته النهائية (اسم) بنداً. r. تم تصميمُ الهقياس بصورة إلكترونية عن

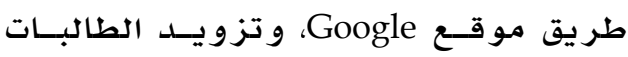
بر ابط المقياس للإجابة عنده

\section{تطبيق تجربة الدراسة}

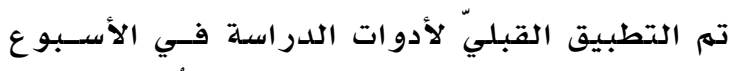

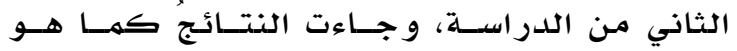

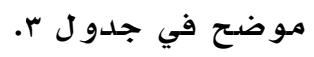

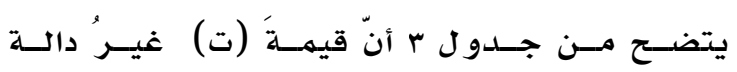

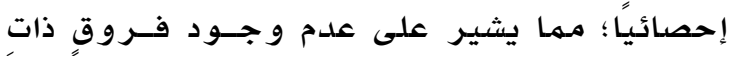

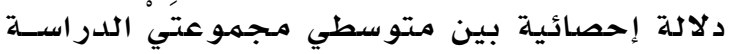

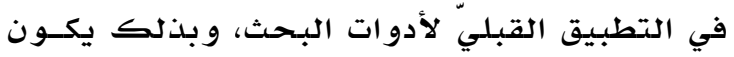

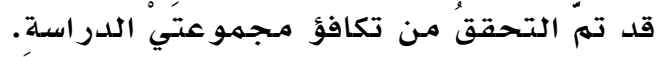

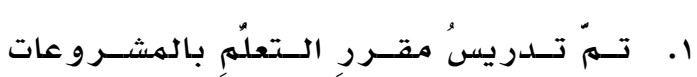

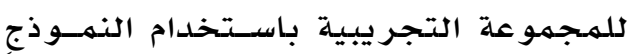

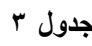

قيم (ت) للفروق بين متوسطي درجات طالبات مجموعتي الاراسة في التطبيق القبلي للأدوات

\begin{tabular}{|c|c|c|c|c|c|c|}
\hline مستوى الدلالة & قيمة ت & الانحراف المعياري & المتوسط الحسابي & العدد العد & المجموعات & 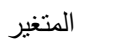 \\
\hline \multirow{2}{*}{$\cdot, 01$} & \multirow{2}{*}{$\cdot, 779$} & $r, 91$ & 10.70 & rq & التجريبية & \multirow{2}{*}{ التفكير الناقد } \\
\hline & & $r, v q$ & $17 . .1$ & rv & الضابطة & \\
\hline \multirow{2}{*}{$\cdot, \vee \vee 9$} & \multirow{2}{*}{ l, VAr } & ir, vo & No,r & rq & التجرييية & \multirow{2}{*}{ فاعلية الذات } \\
\hline & & $1 \varepsilon, \nabla \wedge$ & $\vee ৭, \leqslant 7$ & rv & الضابطة & \\
\hline
\end{tabular}




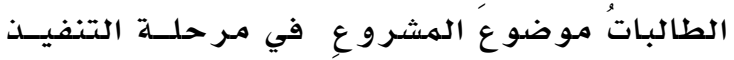

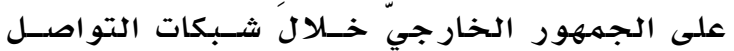

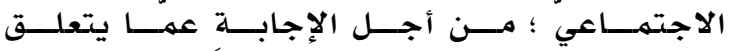

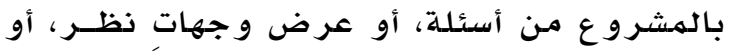

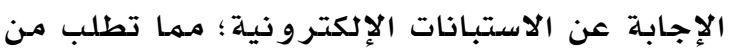

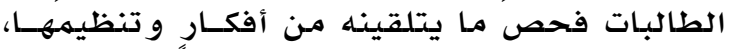

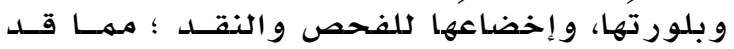
يؤدي إلى تنمية التفكير الناقد لديهن.

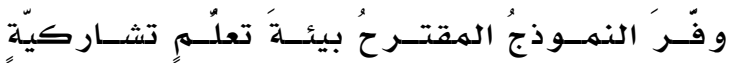

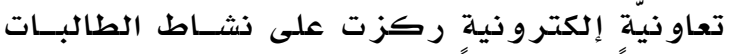

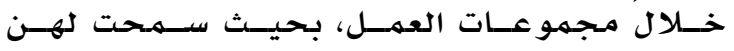
بالبحث و الاكتشاف بأنفسهن، كها أتاحست لهـن التعرض ضلخبرة المباشرة من خلال التفاعلٍِ بين

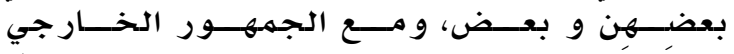

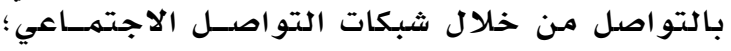

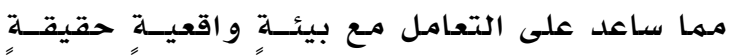

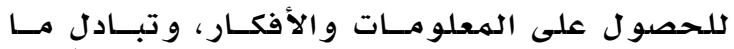

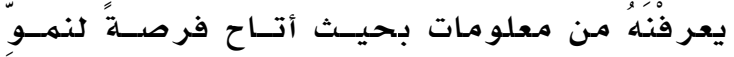

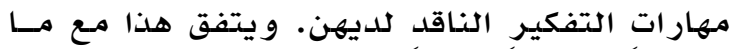

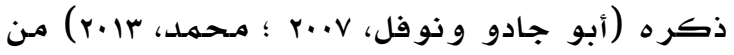

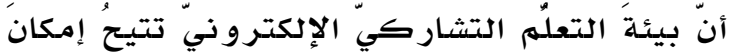

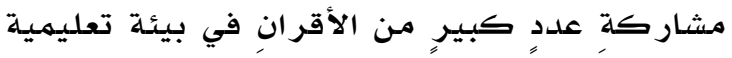

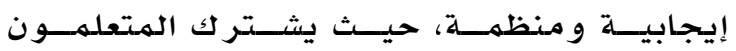
و المعلهم في المـناقشـة، والتحـاور و النقــد، و تبــادل

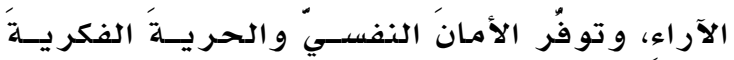

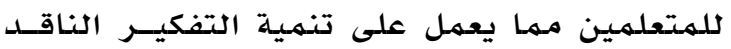

لديهم.

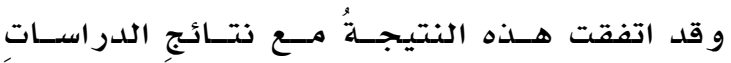
السابقة التي أثبتت فاعلية توظيف أدوات وووسائل

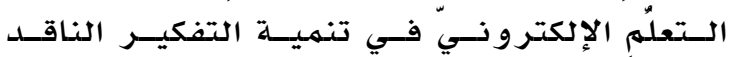

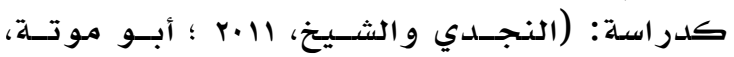

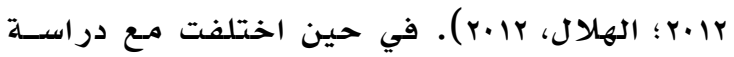

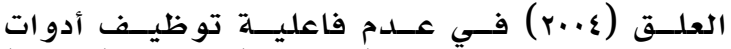

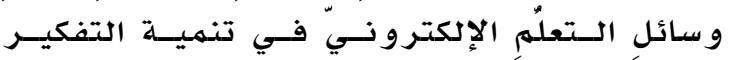

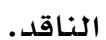

اختبار صحة الفرض الثاني، وينص على أنه: لا

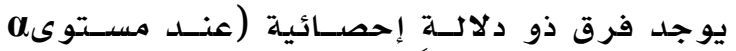

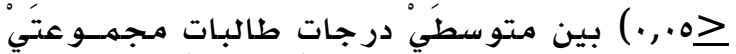
الدراسـة في مقياس فاعلية الذات.
و بذلك تمَّ رفضُ الفرضِ الصفري الأول، وقبول

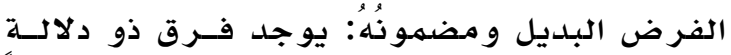

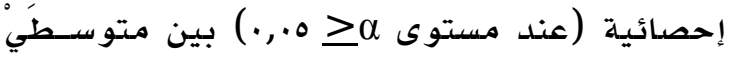

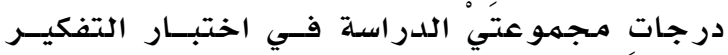
الناقد لصالح الهـمهوعة التجريبية.

و لتقدير حجمٍ فاعلية النموذج المقترح في تنمية

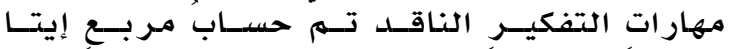

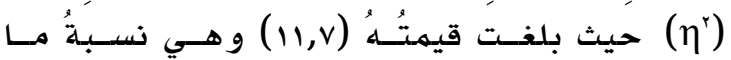

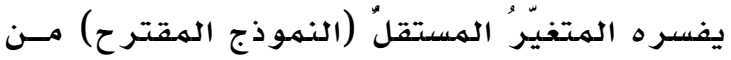

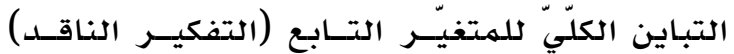

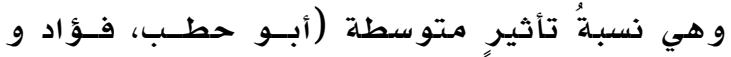

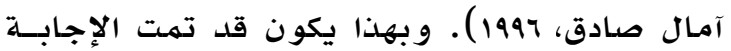
عن السؤال الثاني من أسئلة الدراسلة.

\section{وقد ترجع هذه النتيجة إلى أنه:}

لتكنو لوجيا المعلومات و الاتصالات دورًا محورريّا

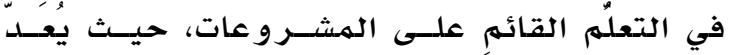

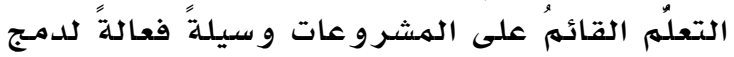

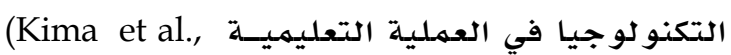

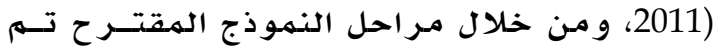

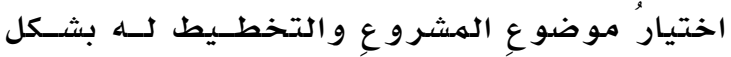

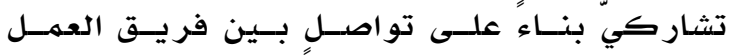

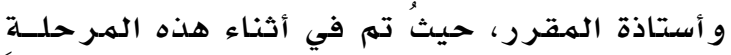

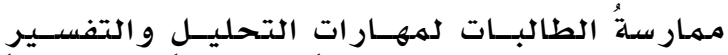

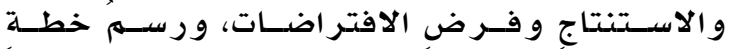

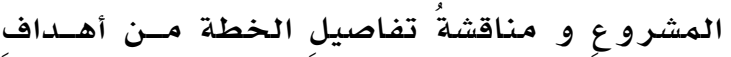
و ألوان النشاط،، و الهعر فة، و الهـهـار ات الهكتســبـة،

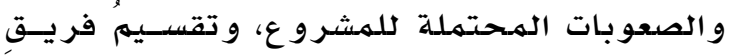

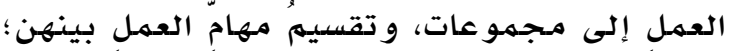
مـما ساعد على وجود تفاعلٍ بين الطالبات بعضهِن

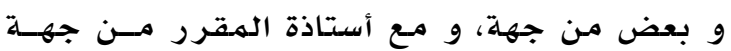

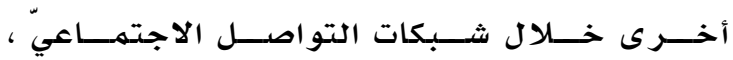
وبالتالي تنميلة التفكير الناقد لديهن، فقد أشارت

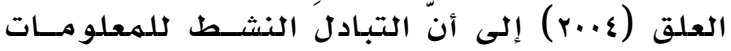

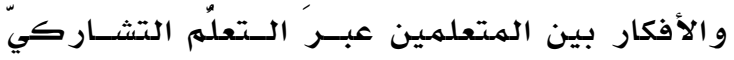

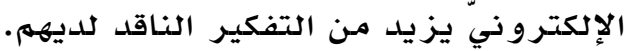
تُعدّ مهاراتُ التفكير الناقد أحدَ السمـات التربويـة

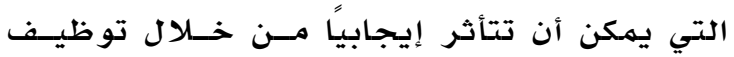

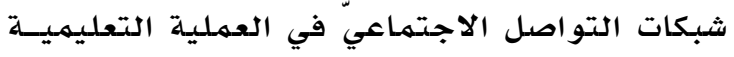

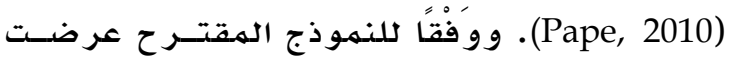




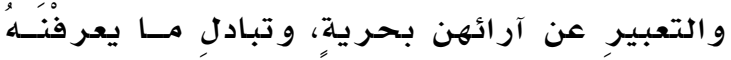

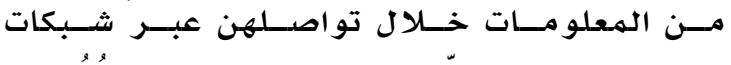

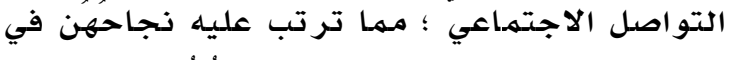

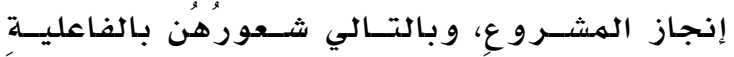
النذاتيـة.

تمثل فاعلية اسـذات إحسدى أهــم مصسـادر دافعيـة

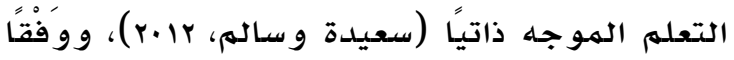

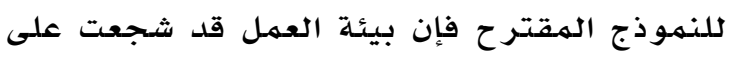

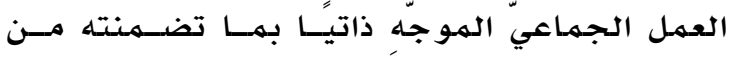

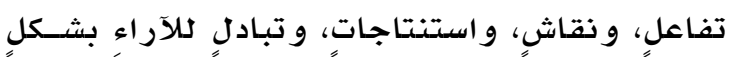

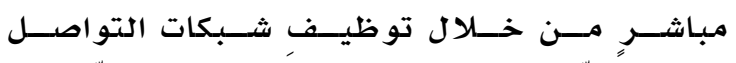

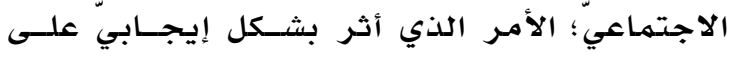

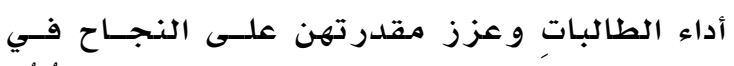

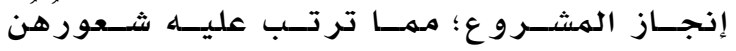
بالفاعلية الذاتية.

وقد اتفقت الدراسـة الحالية مـع نتائج دراسـة

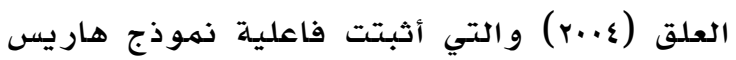
في تصميم الأنشطة الإلكترونية التفاعلية في

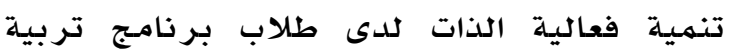
المو هوبين بجامعة الخليج العربي.

التوصيات

ا. العملُ بالنهوذوج المقترح في تدريس مقرر

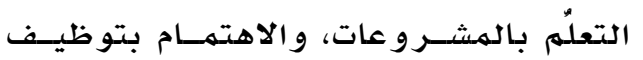

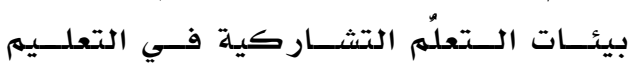
الجامعيّ. r. التشديدُ على تنهيـة مهار ات التفكير الناقــد

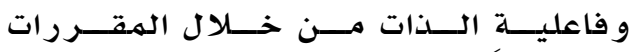

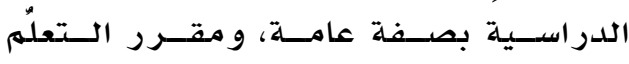

بالهشرو عات بصفة خاصة.

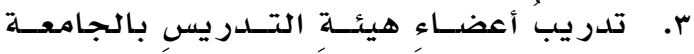

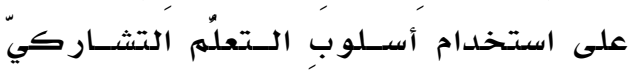
الإلكتر و نيّ و مستحدثاته بشكل دوريّ.

كما تقترح الباحثة إجراءَ البحوثِ التالية:

• دورِ الهقررات الدراسية في الجامعات في

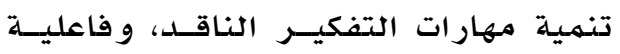
الذات لدى الطالبـات.

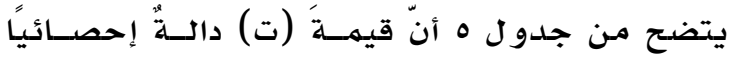

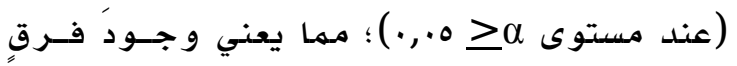

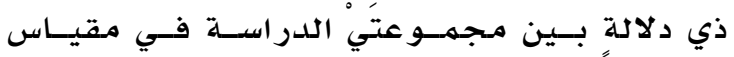

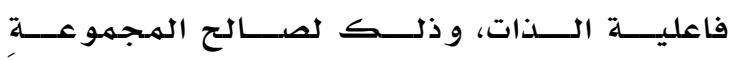

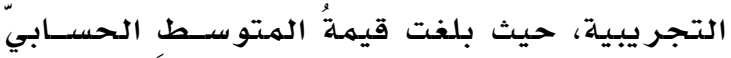

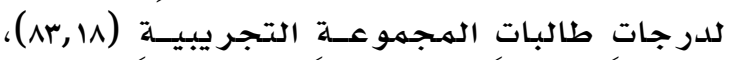

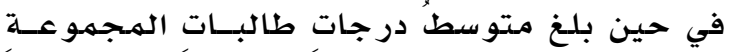

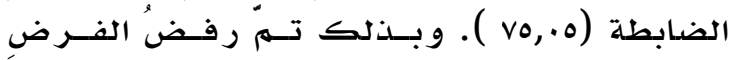

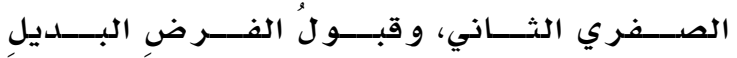

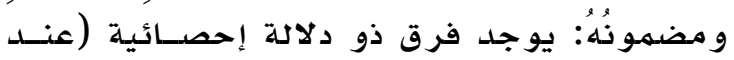

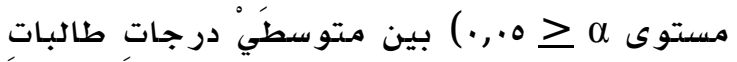

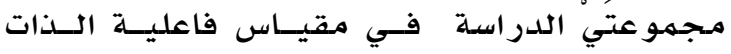
لصالح المهجمو عة التجر يبية.

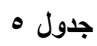

اختبار (ت) لدلالة الفروق بين متوسطي درجات مجموعتي الدراسة في

\begin{tabular}{|c|c|c|c|c|c|}
\hline \multicolumn{6}{|c|}{ مقياس فاعلية الذات البعدي } \\
\hline 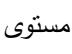 & قيمة & الانحراف & المتوسط & \multirow{2}{*}{ 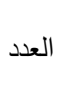 } & \multirow{2}{*}{ المجموعات } \\
\hline 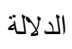 & $ت$ & المعياري & الحسابي & & \\
\hline \multirow{2}{*}{$\cdot, \cdot 1$} & \multirow{2}{*}{$r$, , ^ } & $1 \leqslant, 10$ & ^ז,ו^ & rq & التجريبية \\
\hline & & $1 \leq, r_{4}$ & $v_{0}, .0$ & rV & الضابطة \\
\hline
\end{tabular}

و لتقدير حجمٍ فاعلية النهوذج المقترح في تنمية

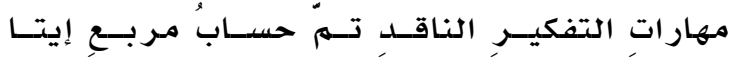

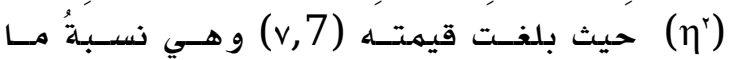

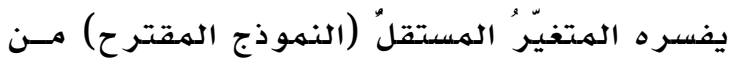

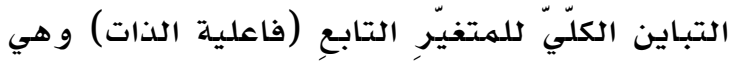

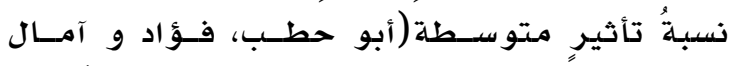

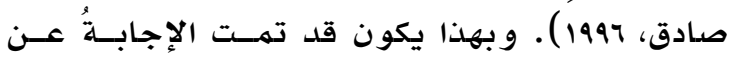
السؤال الثالث من أسئلة الدراسلة ولكون وقد ترجع هذه النتيجة إلى أنه: تؤثر فعاليةُ الذات في أنماط التفكير و التصر فات

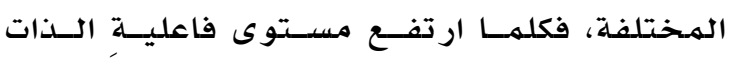

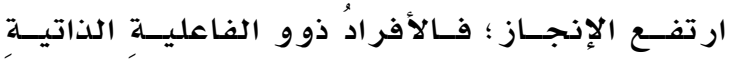

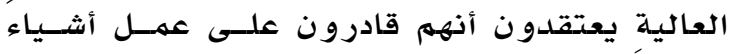

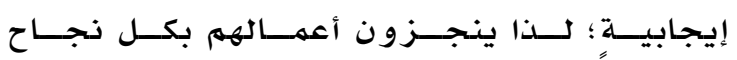

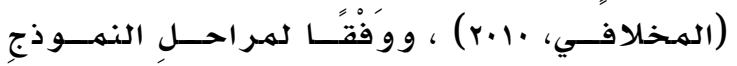

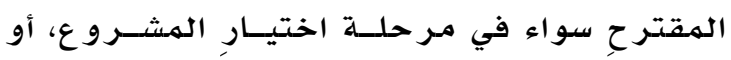

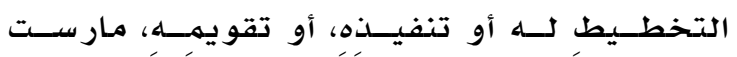

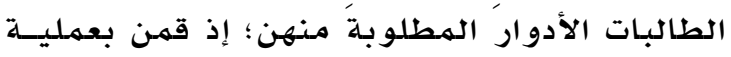

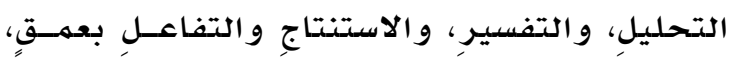




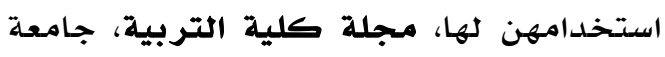

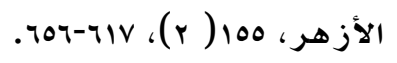

الشايع، حصة محمد و العبيد، أفنان عبد الرحمن

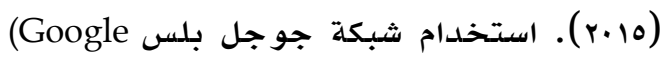

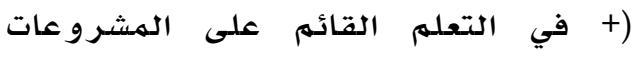

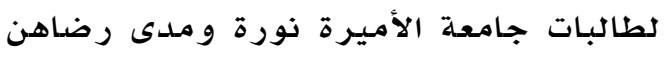
عنها. المجلة الدولية التربوية المتخصصة،

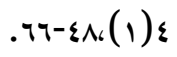

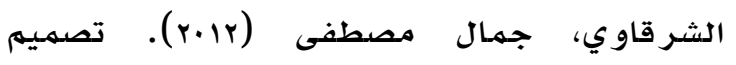
استراتيجية مقترحة لتطوير التعليم المدميج

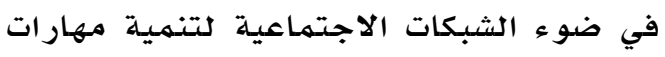

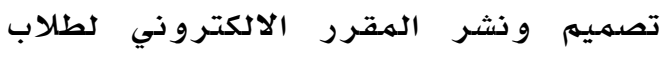
الدراسات العليا بكلية التربية. مجلة الدئة كلية

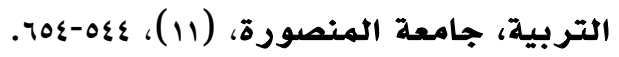

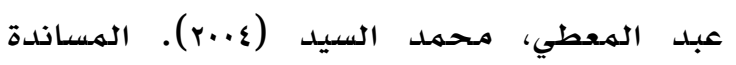
الاجتماعية و المساندة الأكاديمية و فعالية الهاتية

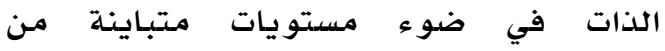
التحصيل الدراسي لدى طلاب الصف الأول

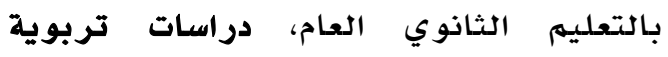

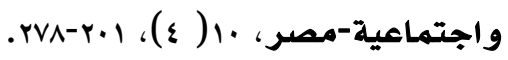

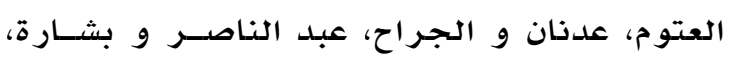

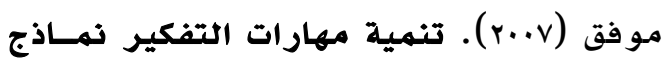

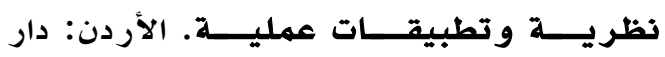

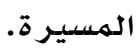

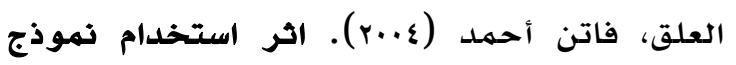

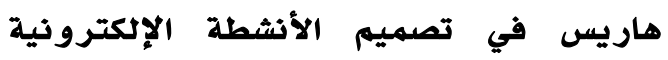
التفاعلية على التفكير الناقد وفعالية الذات

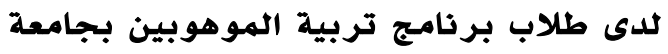

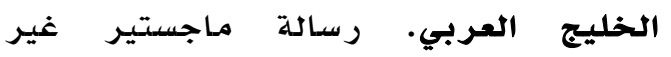

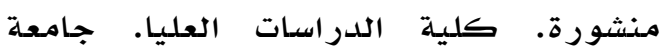
الخليج العربي.

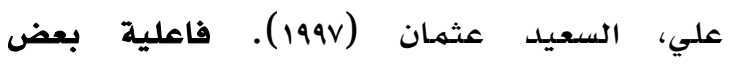
الاستراتيجيات التعليمية على تحصيل طلاب العابي

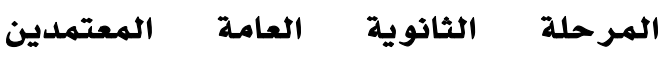

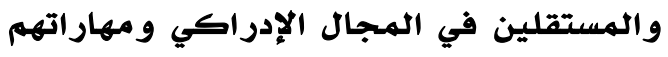

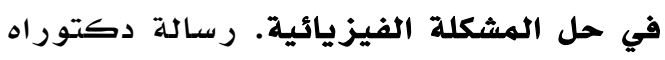
غير منشورة. كلية التربية. جامعة الأزهر.

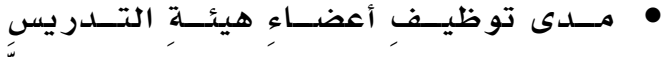

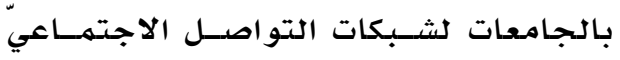
في التدر يس.

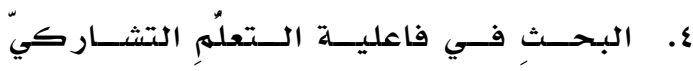
الإلكترو ني في تنمية متغير ات أخرى.

$$
\text { المراجـ }
$$

\section{References}

أبو جادو، صـالح محهـــ و نوفـل، محمهـد بكسر

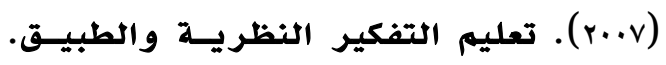
الأردن: دار المسيرة. تعليم التفكير

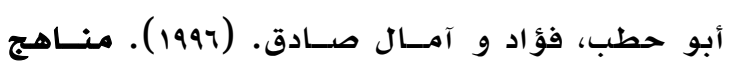
البحث وطرق التحليل الإحصائي في العلوم النفسية والتربوية والاجتماعيـة. القــاهرة: مكتبة الانجلو. أبو موته، حلمي مصـفى (r/r). تطـوير نظــام

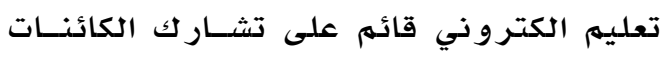

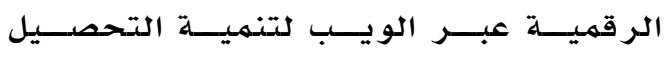

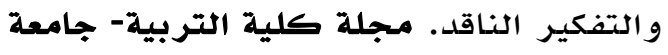

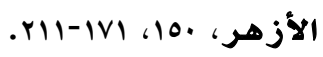
اسماعيل، حمدان محمد (rا.r). تصميم بيئة

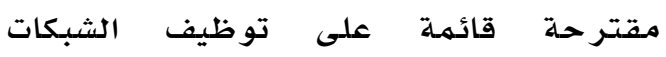

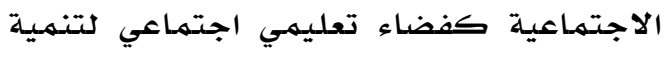

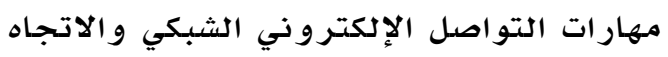

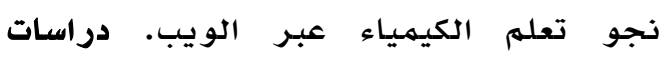

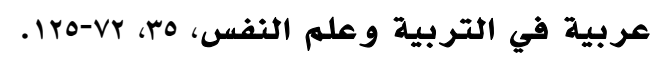
سعيدة، أماني وساله، سيد (Y/.r). أثر التفاعل

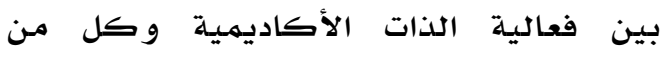

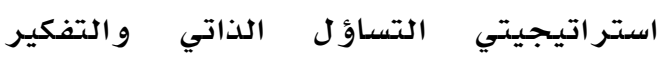

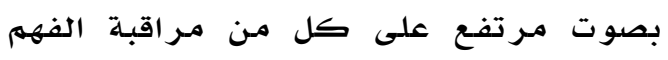

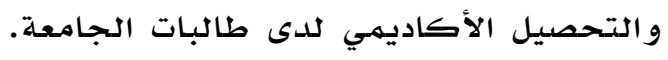

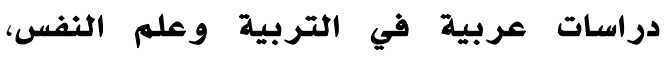

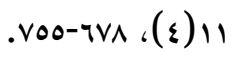
الشايع، حصة محمد و بطيشة، مروة (rا.r).

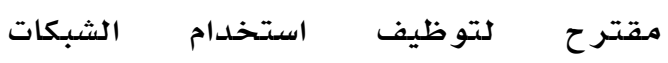

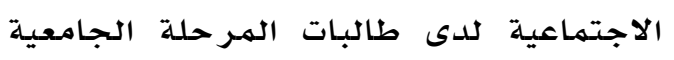

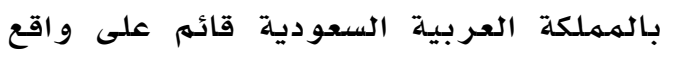




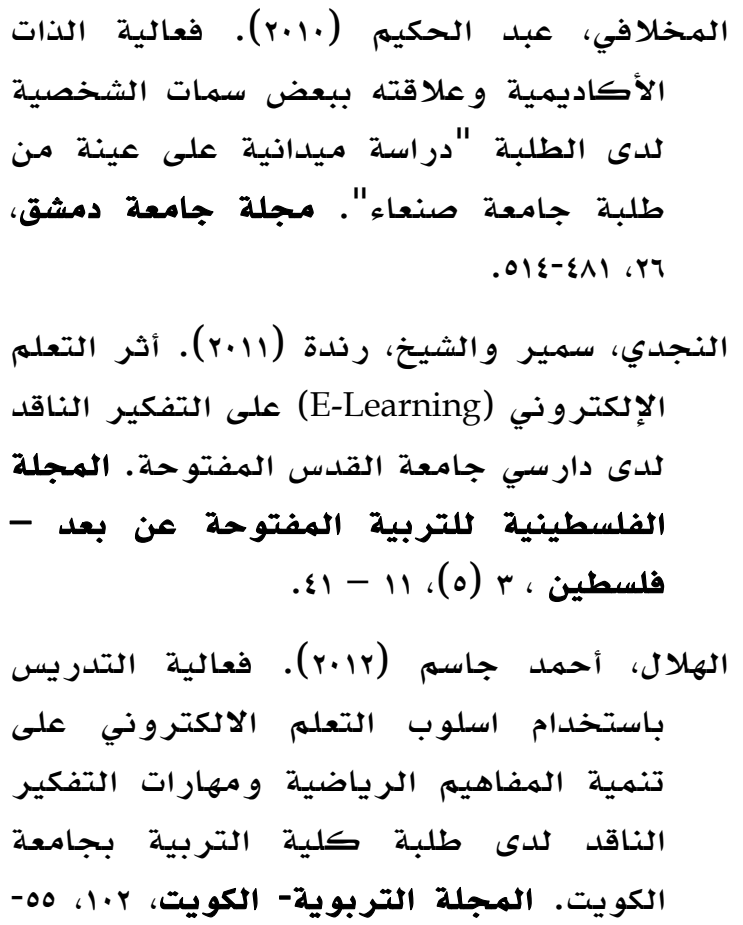

.99

Bandura, A. (2006). Guide for Constructing SelfEfficacy Scales. (available on line), Retrieved May 2014 from http://www.uky.edu/ eushe2/Bandur/ BanduraGuide2006.pdf.

Brown, E. (2011). The Relation Ship Between SelfEfficacy and Educational Expectations in Middle and High School Youth. Unpublished Master Thesis: University of North Carolina Wilmington.

Dunn, K., Rakes, G., and Rakes, T. (2014). Influence of academic self-regulation, critical thinking, and age on online graduate students' academic help-seeking. Distance Education, 35(1), 75-89.

Duze, C. (2010). Effects of Participatory Learning Technique on Achievement and Attitude of B. Ed. Students in Educational Research Methods, Journal Social Science, 22(3), 185-189.

Facione, P. (2011). Critical Thinking: What It Is and Why It Counts. (available on line), Retrieved Apr 2014 from www.insightassessment.com $<\ldots<$ pdf file.

Fisher, A. (2001). Critical Thinking An Introduction. the University Press. Cambridge: the United Kingdom.

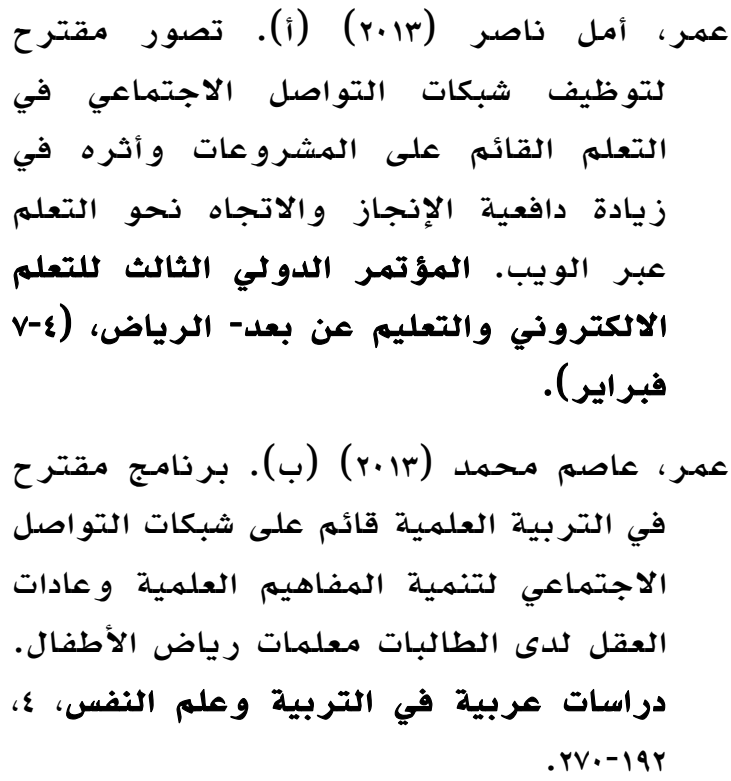


Holmes, B. (2013). School Teachers' Continuous Professional Development in an Online Learning Community: lessons from a case study of an e Twinning Learning Event. European Journal of Education, 48(1), 97-112.

Kima, P., Hong, J., Bonk, C. and Lim, G. (2011). Effects of group reflection variations in project-based learning integrated in a Web 2.0 learning space. Interactive Learning Environments, 19(4), 333-349.

Lovell, E. and Palmer, B. (2013). Engaging Introductory Writing Students Through Facebook Assignments, American College Personnel Association and Wiley Periodicals. About Campus, 18(1), 25-28.

MacKnight, C. (2000). Teaching Critical Thinking through Online Discussions Faculty Can Play a Key Role in Fostering Critical Thinking Among Students Using Web Communication Tools. Educause Quarterly, 4, 38-42.

McNeilla, M., Gospera, M., and Xu, J. (2012), Assessment choices to target higher order learning outcomes: the power of academic empowerment. Research in Learning Technology, 20, 283-296.

Neville, K. and Heavin, C. (2013). Using Social Media to Support the Learning Needs of Future IS Security Professionals, Electronic Journal of e-Learning , 11 (1),29-38.

Pape, L. (2010). Blended Teaching and Learning. Education Digest, 76 ( 2), 22-27.

Thormann, J., Gable, S., Fidalgo, P., and Blakeslee, G. (2013). Interaction, Critical Thinking, and Social Network Analysis (SNA) in Online Courses. The International Review of Research in Open and Distance Learning, 14(3),295-318.

Wood, R. (2002). Critical Thinking. (available on line), Retrieved Apr 2014 from www.robinwood.com /Democracy/. 